\title{
Cohesive Zone Modeling of Fatigue Crack Growth in Brazed Joints
}

\author{
Authors: Morvarid K. Ghovanlou ${ }^{1}$ \\ Hamid Jahed ${ }^{2}$ \\ Amir Khajepour ${ }^{3}$
}

1. Corresponding Author, Dept. of Mechanical and Mechatronics Engineering, University of Waterloo, 200 University Avenue West, Waterloo, Ontario, N2L 3G1, Canada

Email: mkarimig@uwaterloo.ca

2. Professor, Dept. of Mechanical and Mechatronics Engineering, University of Waterloo, 200 University Avenue West, Waterloo, Ontario, N2L 3G1, Canada

Email: hjahed@uwaterloo.ca

3. Professor, Dept. of Mechanical and Mechatronics Engineering, University of Waterloo, 200 University Avenue West, Waterloo, Ontario, N2L 3G1, Canada

Email: a.khajepour@uwaterloo.ca

\begin{abstract}
Fatigue crack growth in low carbon steel brazed joints with copper filler metal is modeled by an irreversible Cohesive Zone Model (CZM). Strain-controlled fatigue tests are performed on the brazed specimens, and the corresponding fatigue crack initiation and propagation lives are recorded. A cyclic damage evolution law is coupled to a bilinear CZM to irreversibly account for the joint stiffness degradation over the number of cycles. The damage law parameters are calibrated based on Irwin's analytical solution and the experimental fatigue crack growth data. Using the characterized irreversible CZM, the fatigue crack growth is simulated and the corresponding fatigue crack growth rates are obtained. The agreement between the numerical results and the experimental data shows the applicability of the CZM to fatigue crack growth analysis and life estimation of brazed joints.
\end{abstract}


Keywords: fatigue crack growth; cohesive zone modeling; brazed joint; damage evolution law; parameter calibration 


\section{Nomenclature}

\begin{tabular}{|c|c|}
\hline$a$ & crack length \\
\hline$A$ & damage evolution law parameter \\
\hline$D_{c}$ & cyclic damage variable \\
\hline$\dot{D_{c}}$ & cyclic damage evolution rate \\
\hline$D_{N}$ & damage variable at cycle $\mathrm{N}$ \\
\hline$E$ & Young's modulus \\
\hline$k$ & cohesive element stiffness \\
\hline$k_{0}$ & cohesive element initial stiffness \\
\hline$K_{I}$ & mode I stress intensity factor \\
\hline$L$ & length of the rod \\
\hline$m$ & damage evolution law parameter \\
\hline$n$ & damage evolution law parameter \\
\hline$N$ & number of cycles \\
\hline$R$ & residual function \\
\hline$T$ & traction \\
\hline$T_{0}$ & CZM fatigue endurance limit \\
\hline$U$ & separation \\
\hline
\end{tabular}


$\dot{U}$

W

$W_{0}$

$\mathcal{E}$

$\varepsilon_{a}$

$\sigma$

$\sigma_{\max , 0}$

$\sigma_{\infty}$ separation rate

displacement

displacement amplitude

axial strain

axial strain amplitude

axial stress

cohesive strength

far-field axial stress 


\section{Introduction}

Brazing as a type of joining is widely used in industries for joining individual components of a structure. A filler metal in the shape of foil, wire, plating, or paste with a melting point of above $450^{\circ} \mathrm{C}$ and below the solidus temperature of the base components is melted and diffused into the surfaces to bond them following solidification [1].

Resistance of brazed joints against propagation of inherent defects and cracks under cyclic loading relies on the joint ductility. Extensive experimental studies have been conducted to investigate fatigue crack initiation and propagation behavior of various brazed joints influenced by the brazing conditions, joint microstructure, and environmental factors [2-7]. However, few researchers have characterized the fatigue behavior of brazed joints using empirical equations. Brossa et al. [8] studied fatigue crack growth (FCG) behavior of AISI 316L brazed joints and obtained the Paris law coefficients based on the corresponding experimental data. Leinenbach et al. [9] characterized the Paris law relation for martensitic stainless steel brazed joints and obtained a large value for the Paris law exponent. As a result, the rate of the FCG was found to be very sensitive to the load ranges.

The Paris law, which correlates the experimental FCG rate to the range of stress intensity factor, is limited to the small scale yielding condition, long cracks, and constant amplitude loading [10]. Despite modifications made to the Paris law, especially for the case of large scale plasticity using the J-integral approach, its applicability to ductile FCG is not always validated by experimental observations [11]. Moreover, experimental investigations indicate the dependency of the interfacial FCG rate on the specimen configuration and loading. For instance, in metallic brazed joints, in which the crack tip plastic zone formed inside the filler metal interlayer is constrained by the surrounding base metals, the size of the plastic zone, which controls the rate of FCG, depends on the interlayer thickness, base and filler metal yield limits, and the type of loading. Conclusively, a Paris law relationship, which is characterized based on experimental FCG data for a specific interfacial joint, loses its transferability to other joint configurations and loading [12].

The cohesive zone model (CZM), as a discrete numerical tool, surpasses most of the limitations involved in the conventional fracture mechanics. This approach is particularly capable of

interface fracture analysis independent of geometry and loading configurations. In this method, 
tractions and separations induced within the crack tip fracture process zone are correlated by an interfacial constitutive law to model crack initiation and propagation [13]. The CZM is characterized by two parameters of so-called cohesive strength and cohesive energy. These two parameters represent the maximum attainable traction within the fracture process zone and the energy needed for complete material separation per unit area of the crack advance, respectively [14]. Applicability of the CZM to fracture analysis of nonlinear structures is the superior advantage of this approach [15]. Particularly, this method is a powerful tool for crack growth analysis at interfaces with complex crack tip fields [12]. Using the CZM, the energy needed for material debonding is decoupled from other dissipative mechanisms within the crack tip process zone. As a result, the CZM characterized for an interface is capable of predicting the experimentally observed geometry and load dependencies of the interfacial crack growth behavior [12].

The CZM approach has been widely applied to model the fracture process at the interfacial joints associated with considerable inelastic deformations $[16,17]$ as well as the composite material structures [18-20]. In recent years, the application of the CZM has been extended to fatigue crack growth analysis especially at interfaces. To this purpose, a damage variable is introduced into the cohesive zone constitutive model to degrade the cohesive stiffness or strength over the number of cycles [11, 12, 21, 22]. Roe and Siegmund [12] were among the first who employed the damage mechanics concept into the CZM and proposed a damage evolution model. Based on their model, Wang and Siegmund [23] simulated the FCG in a ductile metallic layer sandwiched between two elastic substrates. Using the CZM with a unique set of the parameters, they successfully estimated the constraint effect of the elastic substrates on the FCG rate within the ductile layer. This cyclic damage evolution model was later extended to other applications such as FCG analysis in single crystal super alloys [10] and solder joints [24]. Other cyclic damage evolution models, developed based on the accumulated plastic strain or the maximum principal strain, were applied to the fatigue analysis of solder joints and adhesive bonds, as well [14, 25]. To the author's knowledge, the CZM method has not yet been applied to fatigue analysis of brazed joints.

The objective of this paper is to extend the application of the CZM to fatigue crack growth analysis in brazed joints. Strain-controlled fatigue tests are performed on low carbon 
steel/Cu/steel brazed specimens to record the rate of load drop percentage as the crack propagates. Developing a Python script for ABAQUS 6.7 [26], a cyclic damage evolution law is coupled to a bilinear CZM to irreversibly account for the joint stiffness degradation over the number of cycles. The damage law parameters, which affect the FCG behavior in the cohesive zone FE model, are calibrated based on analytical solutions and the experimental data. The characterized irreversible CZM shows applicability to FCG life estimation of the brazed joints.

\section{Material and testing}

Blocks of low carbon steel (ASTM-A36), as the base metal, were furnace brazed using copper filler metal foil $(\mathrm{BCu}-1)$ at the temperature of $1110^{\circ} \mathrm{C}$ [27]. Flat dog-bone shaped fatigue specimens with a thickness of $3 \mathrm{~mm}$ were machined from the brazed blocks. The dimensions of the fatigue specimen are shown in Fig.1.

Fig.1. Dog-bone shaped fatigue specimen with a central joint (dimensions in mm)

Using a servo hydraulic tensile machine, uniaxial strain-controlled fatigue tests with a fully reversed sinusoidal wave form and a frequency of $1 \mathrm{~Hz}$ were performed on the brazed specimens. The specimens were cyclically tested under the strain amplitudes of $0.08 \%, 0.10 \%$, $0.12 \%, 0.15 \%$, and $0.20 \%$. The strain amplitude was measured using a $10-\mathrm{mm}$ gage length axial extensometer. The load over the number of cycles was recorded for each strain amplitude applied to the specimens. A fatigue crack is assumed to initiate when the softening rate of the load-cycle curve accelerates, as shown Fig.2 [28]. The accumulated number of cycles at 50\% load drop is considered as the total fatigue life of the brazed specimens [28].

Fig.2. Load versus the number of cycles for strain amplitudes of (a) $0.08 \%$, (b) $0.10 \%$, (c) $0.12 \%$, (d) $0.15 \%$, and (e) $0.20 \%$

The FCG life and total fatigue life for different strain amplitudes are plotted in Fig.3 (a) and (b), respectively. The test results are summarized in Table 1 . Since the fatigue cracks can easily 
initiate from the joint defects and material flaws, the crack initiation lives are more scattered than the crack propagation lives.

Fig.3. The experimental strain amplitudes versus (a) FCG life, (b) total fatigue life

Table 1. Crack initiation, propagation and total lives for different strain amplitudes

\begin{tabular}{cccccc}
\hline Specimen ID. & $\begin{array}{c}\text { Strain Amp. } \\
\text { [\%] }\end{array}$ & $\begin{array}{c}\text { Initiation life } \\
\text { [cycle] }\end{array}$ & $\begin{array}{c}\text { FCG life } \\
\text { [cycle] }\end{array}$ & $\begin{array}{c}\text { Total life } \\
\text { [cycle] }\end{array}$ & $\begin{array}{c}\text { Final load } \\
\text { drop [\%] }\end{array}$ \\
\hline 3 & 0.20 & 170 & 400 & 570 & 50 \\
4 & 0.15 & 2600 & 1140 & 3740 & 50 \\
5 & 0.15 & 7100 & 1203 & 8303 & 50 \\
6 & 0.12 & 11884 & 4466 & 16350 & 50 \\
1 & 0.10 & 34000 & 11000 & 45000 & 50 \\
2 & 0.10 & 4400 & 9600 & 14000 & 50 \\
10 & 0.08 & 30000 & 12000 & 42000 & 50 \\
\hline
\end{tabular}

Figure 4 (a) shows one of the fatigue crack initiation sites on the Scanning Electron Microscopy (SEM) images of the joint fracture surface. The crack fronts have marked the fracture surface by fatigue striations parallel to the initial crack fronts. As shown in Fig.4 (b), the crack front striations have advanced between the MnS-rich dendrites [27] and the shrinkage microvoids within the copper filler metal interlayer.

Fig.4. SEM macrographs from join fracture surface (a) crack initiation site, (b) interdendritic fatigue striation 


\section{Cohesive zone modeling of fatigue crack growth}

Fatigue crack growth is numerically modeled using an irreversible CZM. A bilinear tractionseparation model is considered for modeling the fracture process within the brazed joint. The characterization of the corresponding model parameters, i.e., the cohesive strength and the cohesive energy has been reported in [29].

In the current study, a damage evolution law is implemented into the constitutive equation of the cohesive elements to irreversibly account for the cohesive zone stiffness degradation due to cyclic loading. The parameters related to the rate of damage evolution are calibrated based on analytical solutions and the experimental FCG data.

\subsection{Cyclic damage evolution}

A cyclic damage evolution law, proposed by Bouvard et al. [10], is applied to this study. This damage law which was motivated based on Roe and Siegmund's model is:

$$
\dot{D_{c}}=A\left(1-D_{c}\right)^{m}\left\langle\frac{T}{1-D_{c}}-T_{0}\right\rangle^{n}\|\dot{U}\|
$$

where $A, m$ and $n$ are the parameters which control the rate of damage evolution, and $T_{0}$ is a traction threshold or the CZM fatigue endurance limit under which the damage variable does not evolve [10]. Moreover, the rate of change in separation within the cohesive zone is indicated by $\dot{U}$. Value of the damage evolution rate for cycle (i) is explicitly calculated as $\dot{D}_{c, i}=\dot{D}_{c}\left(T_{(i-1)}, \dot{U}_{(i-1)}, D_{c,(i-1)}\right)$, and the amount of the damage is accumulated at the end of the cycle as follows:

$$
D_{c, i}=D_{c,(i-1)}+\dot{D}_{c, i} \cdot d N
$$

The stiffness of the cohesive zone, $k$, degrades due to damage accumulation in each cycle (i), as below:

$$
k_{i}=k_{0}\left(1-D_{c, i}\right)
$$

where $k_{0}$ is the initial stiffness of the CZM.

Figure 5 shows the fully reversed sinusoidal displacement, $w(t)$, applied to the specimens and the corresponding loading, unloading and reloading paths on the traction-separation model. The 
damage initiates if the tractions reaches the cohesive strength, and evolves on the monotonic softening path during the first loading cycle. It is assumed that the unloading paths on the traction-separation law are always toward the origin [10]. The cyclic damage evolves during loading when the tractions are positive, and remains constant during unloading [24].

Fig.5. Applied displacement wave, w(t), and the corresponding loading-unloading paths on the traction-separation model

Since the damage evolution has to be accounted for each cycle, the fatigue analysis would be a time consuming procedure. Therefore, the FE analysis is only performed for a selected number of cycles and the damage variable is extrapolated for the next $\Delta N$ cycles, as follows:

$$
D_{N+\Delta N} \approx D_{N}+\frac{d D_{N}}{d N} \Delta N
$$

The cycle increment, $\Delta N$, in damage extrapolation relation is selected such that the damage increment $\left(D_{N+\Delta N}-D_{N}\right)$ is sufficiently small $[10,11]$.

\subsection{Implementation of the damage evolution law into the FE model}

In order to implement the cyclic damage evolution law into the cohesive zone constitutive model, a script was developed for ABAQUS 6.7 in Python language to account for the cohesive element stiffness degradation over the number of cycles. In this procedure, the joint traction, i.e., the stress normal to the crack faces, and separation, i.e., the relative opening displacement of the crack faces, are taken from output database of the FE analysis and used to calculate the damage evolution in each cycle. The stiffness of the cohesive elements, which is degraded due to accumulation of the damage variable, is reassigned to the model for analysis of the next cycle. Figure 6 shows the flowchart of the Python script developed for damage analysis for each cycle (i).

Fig.6. Flowchart of the cyclic damage analysis 


\subsubsection{Numerical study}

The Python script, which accounts for the cohesive element stiffness degradation, is validated by comparing FE results with the analytical solution available for a simple uniaxial problem. In this example a rod with a central joint under a fully reversed uniaxial cyclic loading is considered, as shown in Fig.7. The rod has a length and radius of $0.02 \mathrm{~mm}$ and $0.01 \mathrm{~mm}$, respectively. The material properties and cyclic damage law parameters used in the analysis are listed in Table 2.

Fig.7. A rod with a central butt joint under cyclic loading

Table 2. Material properties and damage law parameters used in the analysis

\begin{tabular}{cc}
\hline Parameter & Value \\
\hline Young's modulus [GPa $]$ & 30 \\
Poisson's ratio & 0.25 \\
$\boldsymbol{k}_{\mathbf{0}}\left[\frac{\mathbf{G P a}}{\mathbf{m m}}\right]$ & $1 \mathrm{e} 9$ \\
$\boldsymbol{A}\left[\mathbf{M P a}^{-\mathbf{1}} \cdot \mathbf{m m}^{-\mathbf{1}}\right]$ & 3000 \\
$m$ & 3 \\
$n$ & 1 \\
$\mathbf{T}_{\mathbf{0}}[\mathbf{M P a}]$ & 100 \\
\hline
\end{tabular}

The uniaxial cyclic displacement, applied to the one end of the rod, is described by:

$$
w(t)=W_{0} \sin \left(\frac{\pi t}{2}\right)
$$

where the value of $W_{0}$ is equal to $0.0002 \mathrm{~mm}$.

A linear traction-separation law, Eq. (6), is considered as the joint constitutive model. For the sake of simplicity of solving this example, it is assumed that the maximum traction never reaches the cohesive strength.

$$
T=k_{0}\left(1-D_{c}\right) U
$$

Considering a linear elastic behavior for the rod, the axial stress, $\sigma$, is expressed in terms of the joint separation, $U$ by: 


$$
\sigma=\frac{(w-U)}{L} E
$$

where $E$ is Young's modulus of the rod.

The traction induced in the joint is equal to the axial stress in the rod $(T=\sigma)$ to satisfy the continuity requirement. Substituting Eq. (6) into Eq. (7), the separation within the joint is obtained from [24]:

$$
U=w /\left[1+\frac{k L}{E}(1-D)\right]
$$

Using the analytical solution presented above, a MATLAB code is written for cycle by cycle analysis of this problem.

Figure 8 shows the axisymmetric FE model of the rod and the applied boundary conditions. One end of the rod is fixed and the axial displacement is applied to the other end of the model. The rod and joint regions are meshed by 4-node bilinear axisymmetric quadrilateral continuum elements (CAX4R) and 4-node axisymmetric cohesive elements (COHAX4), respectively.

Fig.8. Axisymmetric FE model of the rod under uniaxial loading

Using the Python script, the joint traction and separation are taken from output database of the FE analysis to be involved in the calculation procedure provided in Fig. 6.

The damage variables obtained from the FEM and analytical solution are plotted and compared in Fig.9. It is observed that the damage evolves rapidly at the beginning and propagates slower during the last cycles until it reaches the critical value of 1 . Cyclic by cycle traction-separation obtained from the FEM and the analytical solution are plotted in Fig.10. The figure shows the gradual degradation of the cohesive stiffness over the number of cycles. The good agreement between the results of the FEM and the analytical solution validates the accuracy of the Python script developed for the cyclic FE analysis. This script will now be used for modeling fatigue crack growth in the brazed joints.

Fig.9. Damage evolution over the number of cycles from the FEM and analytical solution for butt joined rod problem

Fig.10. Cyclic traction-separation curves from the FEM and analytical solution for butt joined rod problem 


\subsection{Calibration of the cyclic damage evolution law}

In this section FCG in the brazed specimens is modeled using the Python script developed for the cyclic damage analysis in ABAQUS 6.7. The percentage of the load drop is considered as an indication of fatigue crack extension in the analysis. The initial crack length at the beginning of load drop is estimated by the FEM. Then, cycle by cycle FE analysis is performed to account for damage evolution and cohesive element stiffness degradation. The loss of load bearing capacity in fully damaged cohesive elements simulates fatigue crack propagation.

\subsubsection{Estimation of the initial fatigue crack length}

The fatigue specimens with different crack lengths, $a$, are modeled in ABAQUS to estimate the fatigue crack length at the initiation of load drop. One row of the cohesive elements (COH2D4) is placed along the joint interlayer, as shown in Fig.11. The surrounding base metal regions are modeled in plane stress condition using 4-node quadrilateral bilinear elements (CPS4R) [26]. Elastic properties of the base metal are Young's modulus of $200 \mathrm{GPa}$ and Poisson's ratio of 0.3. The hardening behavior of the base metal is taken from the tensile tests and the corresponding stress values versus the plastic strains are provided in Table 3. The cohesive zone properties of the filler metal interlayer, i.e., the cohesive strength and the cohesive energy are taken equal to $400 \mathrm{MPa}$ and $6.3 \mathrm{~kJ} / \mathrm{m}^{2}$, respectively [29].

Table 3. The stress values versus the plastic strains for the base metal

\begin{tabular}{ccccccccc}
\hline $\begin{array}{c}\text { Plastic strain } \\
{[\mathbf{m m} / \mathbf{m m}]}\end{array}$ & 0 & 0.014 & 0.030 & 0.040 & 0.050 & 0.060 & 0.070 & 0.100 \\
\hline Stress [MPa] & 219 & 220 & 270 & 290 & 308 & 322 & 332 & 360 \\
\hline
\end{tabular}

Fig.11. FE model of the fatigue specimen with an initial crack

In order to investigate the effect of the initial crack length on the load capacity of the specimen, several FE models with different crack lengths are considered. Applying the same amount of axial displacements to the FE models, the corresponding reaction forces are obtained. The load drop percentage is calculated with respect to the load level in an intact model and plotted over the crack length in Fig.12. This figure shows that the existence of the crack affects the load 
capacity of the model and the load drop accelerates at the crack length of $0.1 \mathrm{~mm}$. Hence, for the purpose of FCG simulation an initial crack with the length of $0.1 \mathrm{~mm}$ is created in the model.

Fig.12. Load drop percentage versus the crack length created in the FE model

\subsubsection{Determination of the damage law parameters}

The damage law parameters, which affect the rate of damage evolution in the FE model, are calibrated based on Irwin's analytical solution and the experimental FCG data. Fatigue crack growth is simulated by successive degradation of the cohesive elements in the FE model. The 10-mm gage section of the fatigue specimen with the initial crack length of $0.1 \mathrm{~mm}$ within the brazed joint is modeled, as shown in Fig.13. The axial deformation within the gage section, which is experimentally measured by the extensometer, is applied as the boundary condition of the model.

Fig.13. FE model of the fatigue specimen with an initial crack

The cohesive element size in the FE model is selected based on the criterion proposed by McClung and Sehitoglu [30]. According to this criterion, there have to be at least 10 elements along the crack tip plastic zone to obtain accurate results. Using McClung's criterion on the fracture process zone (FPZ), the length of the cohesive elements, $L_{e, C Z M}$, is selected such that:

$$
L_{e, C Z M} \leq 0.1 L_{F P Z}
$$

where $L_{F P Z}$ is the length of the fracture process zone [10].

The length of the FPZ can be estimated based on Irwin's theory for plastic zone size. In the plane stress condition, Irwin's analytical solution yields the following equation:

$$
\begin{gathered}
L_{F P Z}=\frac{1}{\pi}\left(\frac{K_{I}}{T_{0}}\right)^{2} \\
K_{I}=1.12 \sigma_{\infty} \sqrt{\pi a}
\end{gathered}
$$

where $\sigma_{\infty}$ is the far field axial stress and $a$ is the crack length [10, 31]. 
In order to obtain the maximum allowable length of the cohesive elements, a minimum value of the stress intensity factor, which corresponds to the initial crack length of $0.1 \mathrm{~mm}$ and the strain amplitude of $0.10 \%$, is calculated and presented in Table 4 . The value of the CZM fatigue endurance limit, $T_{0}$, is taken equal to $T_{0}=0.25 \sigma_{\max , 0}$ [12]. The length of the FPZ and the maximum size of the cohesive elements are obtained equal to $0.3920 \mathrm{~mm}$ and $0.0392 \mathrm{~mm}$, respectively. Therefore, the selected length of $0.015 \mathrm{~mm}$ for the cohesive elements in the FE model satisfies McClung's criterion.

Table 4. Calculation of the maximum size of the cohesive elements

\begin{tabular}{ccccccc}
\hline$\varepsilon_{\boldsymbol{a}}[\%]$ & $\boldsymbol{\sigma}_{\infty}[\mathbf{M P a}]$ & $\boldsymbol{a}[\mathbf{m m}]$ & $\boldsymbol{K}_{\boldsymbol{I}}[\mathbf{M p a} \sqrt{\boldsymbol{m}}]$ & $\boldsymbol{T}_{\mathbf{0}}[\mathbf{M P a}]$ & $\boldsymbol{L}_{\boldsymbol{F P Z}}[\mathbf{m m}]$ & $\boldsymbol{L}_{\boldsymbol{e}, \boldsymbol{C Z M}}[\mathbf{m m}]$ \\
\hline 0.10 & 198 & 0.1000 & 3.5095 & 100 & 0.3920 & 0.0392 \\
\hline
\end{tabular}

The parameter $m$, which controls the damage rate, affects the length of the FPZ. Thus, this parameter is calibrated such that the length of the FPZ obtained from the FEM conforms to that of the analytical solution. According to Roe and Siegmund's damage law the exponent of the term $\left\langle\frac{T}{1-D_{c}}-T_{0}\right\rangle$, i.e., the value of the parameter $n$ in Eq. (1), is set equal to unity [12]. Using the parameters listed in Table 5, cycle by cycle FE analysis is performed for the strain amplitude of 0.15\%. Figure 14 shows the far-field stress and traction distribution obtained for the crack length of $0.1 \mathrm{~mm}$. The length of the FPZ is taken form the material crack tip to the mathematical crack tip [10]. The numerical and analytical lengths of the FPZ for different stages of the crack propagation are plotted in Fig. 15. The results show that using the value of 1.75 for the parameter $m$ provides numerical results that are in good agreement with the analytical solution.

Table 5. Parameters used in FCG analysis

\begin{tabular}{ccccc}
\hline $\boldsymbol{k}_{\mathbf{0}}[\mathrm{GPa} / \mathbf{m m}]$ & $\boldsymbol{A}\left[\mathrm{MPa}^{-\mathbf{1}} \cdot \mathbf{m m}^{-\mathbf{1}}\right]$ & $\boldsymbol{n}$ & $\boldsymbol{\sigma}_{\max , \mathbf{0}}[\mathbf{M P a}]$ & $\boldsymbol{T}_{\mathbf{0}}[\mathbf{M P a}]$ \\
\hline 1640 & 0.05 & 1 & 400 & 100 \\
\hline
\end{tabular}

Fig.14. Traction and far-field stress along the interface

Fig.15. Analytical and numerical FPZ length with respect to the crack length for $m=1.75$ 
In order to calibrate the parameter $A$ of the cyclic damage evolution law, the rate of the load drop is plotted for the strain amplitudes of $0.12 \%, 0.15 \%$ and $0.20 \%$, and compared with the FE simulation results, as shown in Fig.16. The value of the parameter $A$ for each strain amplitude is obtained such that the FE results best fit the corresponding experimental data. The values of the parameter $A$ obtained for different strain amplitudes are listed in Table 6.

Fig.16. Experimental and numerical load drop rate for different strain amplitudes

Table 6. Values of the parameter $A$ obtained for different strain amplitudes

\begin{tabular}{cc}
\hline $\boldsymbol{\varepsilon}_{\boldsymbol{a}}[\%]$ & $\boldsymbol{A}\left[\mathrm{MPa}^{-\mathbf{1}} \cdot \mathbf{\mathbf { m m } ^ { \mathbf { 1 } } ]}\right.$ \\
\hline 0.12 & 0.009 \\
0.15 & 0.031 \\
0.20 & 0.060 \\
\hline
\end{tabular}

An average value for the parameter $A$ is calculated based on the least squares method as follows:

$$
R=\sum_{i=1}^{3}\left(A_{i} \varepsilon_{i}-\bar{A} \varepsilon_{i}\right)^{2}
$$

where the value of $\bar{A}$ is obtained such that to minimize the residual function of $R$, as bellow:

$$
\begin{gathered}
\frac{\partial R}{\partial \bar{A}}=0 \\
\bar{A}=\frac{\sum_{i=1}^{3} A_{i} \varepsilon_{i}}{\sum_{i=1}^{3} \varepsilon_{i}}
\end{gathered}
$$

Using Eq. (14), the value of $\bar{A}$ is obtained equal to 0.037 . 


\section{Results and discussion}

The cyclic damage evolution law was calibrated based on Irwin's analytical solution on the fracture process zone and the experimental data. The value of the CZM fatigue endurance limit was assumed to be equal to $0.25 \sigma_{\max , 0}$. The values of the parameter $m$ and $A$ were obtained equal to 1.75 and 0.037 , respectively. Using the calibrated damage evolution law, the FCG is simulated in this section. Figure 17 shows the contours of the traction and stress perpendicular to the crack faces (S22) for the strain amplitude of $0.15 \%$ at the number of cycles of 2, 500, and 800.

Fig.17. Contours of axial stress (S22) around the crack tip for $\varepsilon_{a}=0.15 \%$ at (a) $\mathrm{N}=2$ cycles, (b) $\mathrm{N}=500$ cycles, (c) $\mathrm{N}=800$ cycles

The traction distributions from the initial crack tip along the joint interface are shown in Fig. 18. Also, the corresponding distributions of the damage variable and the cohesive stiffness are plotted in Fig. 19 and Fig. 20, respectively. The results show that at the beginning of the loading, the damage has slightly evolved within the crack tip cohesive elements which results in the traction decrease. Continuing the cyclic loading, the damage propagates through the crack tip cohesive elements and the cohesive stiffness decreases accordingly. Once the damage variable reaches the critical value of 1 , the cohesive elements are fully degraded and totally lose their load bearing capacity which simulates crack propagation.

Fig.18. Traction distributions along the interface for $\varepsilon_{a}=0.15 \%$ at different cycles

Fig.19. Damage distributions along the interface for $\varepsilon_{a}=0.15 \%$ at different cycles

Fig.20. Cohesive stiffness distributions along the interface for $\varepsilon_{a}=0.15 \%$ at different cycles 
The rate of fatigue crack growth, $\frac{d a}{d N}$, over the number of cycles, $N$, obtained form the calibrated irreversible CZM is plotted in Fig. 21. It is shown that the higher strain amplitude, the faster the crack propagation along the interlayer.

Fig.21. Crack growth rate with respect to number of cycles obtained from the CZM

Figure 22 shows the experimental strain amplitude-FCG life curve in comparison to the results obtained from the irreversible CZM. The predicted results are in good agreement with the experimental ones, which shows the applicability of the CZM to fatigue analysis of the brazed joints.

Fig.22. Experimental strain-FCG life curve in compared to the CZM results

\section{Concluding remarks}

The CZM method was applied to fatigue crack growth analysis in brazed joints. A damage evolution law was coupled to the bilinear CZM and calibrated to irreversibly account for the cohesive zone stiffness degradation and simulate FCG behavior within the brazed joint. The following conclusions are drawn from this study:

1. Fatigue failure behavior of the brazed joints is characterized by performing fully reversed strain controlled cyclic tests. Interdendritic fatigue striations observed on the SEM images taken from the joint fracture surface reveal the joint failure mechanism under cyclic loading.

2. Developing a Python script for ABAQUS 6.7, a cyclic damage evolution law is implemented into the constitutive equation of the bilinear CZM to degrade the joint stiffness. The accuracy of the script is validated by comparing results of the FE modeling of a simple uniaxial problem with that of the corresponding analytical solution. 
3. The damage evolution law parameters are calibrated based on Irwin's analytical solution on the fracture process zone and the experimental data. A proper size for the cohesive elements is selected based on McClung's criterion on the fracture process zone.

4. Using the characterized irreversible CZM, the FCG for different strain amplitudes is simulated and the corresponding fatigue crack growth rates are obtained. It is shown that the higher strain amplitude, the faster the crack propagation along the interlayer. The agreement between the predicted results and the experimental data shows the applicability of the CZM to fatigue crack growth analysis and life estimation of brazed joints away from limitations associated with other approaches.

\section{Acknowledgment}

The authors would like to acknowledge the financial support of the Natural Sciences and Engineering Research Council of Canada, NSERC Strategic Grant Program, in this study. 


\section{References}

[1] R.W. Messler, Joining of Materials and Structures, Elsevier, USA, 2004.

[2] Y.H. Yu, M.O. Lai, Effects of gap filler and brazing temperature on fracture and fatigue of wide-gap brazed joints, J. Mater. Sci. 30 (1995) 2101-2107.

[3] F. Gao, Y. Qiana, Micromechanical properties of heterogeneous aluminum-silicon brazed joint, Mater. Lett. 58 (2004) 2861-2866.

[4] H.D. Solomon, A statistical analysis of brazed joint fatigue behaviour, Weld. Res. Suppl (2001) 148-156.

[5] Y.X. Gan, H.A. Aglan, R.V. Steward, B.A. Chin, Fatigue failure mechanisms of vanadium alloy/stainless steel brazed joints, J. Mater. Sci. Lett. 20 (2001) 1909-1911.

[6] N.K. Mukhopadhyay, S. Ghsh Chowdhury, G. Das, An investigation of the failure of low pressure stream turbine blades, Eng. Fail. Anal. 5 (3) (1998) 181-193.

[7] J.N. Waddell, I. Ichim, H. Lee, L. Fangtao, Fatigue failures of bar-attachment brazed joints for implant-supported over dentures, Eng. Fract. Mech. 74 (2007) 1148-1159.

[8] M. Brossa, E. Franconi, U. Guerreschi, L. Pierazzi, P. Poggi, V. Rustia, Pre- and postirradiation properties of brazed joints of AISI 316L stainless steel, J. Nucl. Mater. 212215 (1994) 1574-1578.

[9] C. Leinenbach, H.J. Schindler, T.A. Baser, N. Rüttimann, K. Wegener, Fracture behaviour and defect assessment of brazed steel joints, $17^{\text {th }}$ European conference on fracture, Brno, Czech Republic, 2008, pp. 2121-2128.

[10] J.L. Bouvard, J.L. Chaboche, F. Feyel, F. Gallerneau, A cohesive zone model for fatigue and creep-fatigue crack growth in single crystal super alloys, Int. J. Fatigue 31 (2009) 868-879.

[11] A. de-Andres, J.L. Perez, M. Ortiz, Elastoplastic finite element analysis of threedimensional fatigue crack growth in aluminum shafts subjected to axial loading, Int. J. Solids Struct. 36 (1999) 2231-2258.

[12] K.L. Roe, T. Siegmund, An irreversible cohesive zone model for interface fatigue crack growth simulation, Eng. Fract. Mech. 70 (2003) 209-232.

[13] A. Needleman, A continuum model for void nucleation by inclusion debonding. J. Appl. Mech. 54 (1987) 525-531.

[14] Q.D. Yang, D.J. Shim, S.M. Spearing, A cohesive zone model for low cycle fatigue life prediction of solder joints. Microelec. Eng. 75 (2004) 85-95.

[15] J.L. Chaboche, F. Feyel, Y. Monerie, Interface debonding models: a viscous regularization with a limited rate dependency. Int. J. Solids Struct. 38 (2001) 3127-3160. 
[16] V. Tvergaard, J.W. Hutchinson. On the toughness of ductile adhesive joints. J. Mech. Phys. Solids 44 (1996) 789-800.

[17] Q.D. Yang, M.D. Thouless, S.M. Ward, Elastic-plastic mode II of adhesive joints, Int. J. Solids Struct. 38 (2001) 3251-3262.

[18] Q. Yang, B. Cox, Cohesive models for damage evolution in laminated composites. Int. J. Fract. 133 (2005) 107-137.

[19] C. Fan, P.Y. Ben Jar, J.J.R. Cheng, Cohesive zone with continuum damage properties for simulation of delamination development in fiber composites and failure of adhesive joints. Eng. Fract. Mech. 75 (2008) 3866-3880.

[20] D. Xie, A.G. Salvi, C. Sun, A.M. Waas, Discrete Cohesive Zone Model to Simulate Static Fracture in 2D Triaxially Braided Carbon Fiber Composites. J. Compos. Mater. 40 (2006) 2025-2046.

[21] O. Nguyen, E.A. Repetto, M. Ortiz, R.A. Radovitzky, A cohesive model of fatigue crack growth, Int. J. Fract. 110 (2001) 351-369.

[22] B. Yang, S. Mall, K. Ravi-Chander, A cohesive zone model for fatigue crack growth in quasibrittle materials, Int. J. Solids Struct. 38 (2001) 3927-3944.

[23] B. Wang, T. Siegmund, A numerical analysis of constraint effects in fatigue crack growth by use of an irreversible cohesive zone model, Int. J. Fract. 132 (2005) 175-196.

[24] A. Abdul-Baqi, P.J.G. Schreurs, M.G.D. Geers, Fatigue damage modeling in solder interconnects using a cohesive zone approach, Int. J. Solids Struct. 42 (2005) 927-942.

[25] H. Khoramishad, A.D. Crocombe, K.B. Katnam, I.A. Ashcroft, Predicting fatigue damage in adhesively bonded joints using a cohesive zone model, Int. J. Fatigue 32 (2010) 1146-1158.

[26] ABAQUS/CAE, Version 6.7-1, Dassault Systems, 2007.

[27] M.K. Ghovanlou, H. Jahed, A. Khajepour, Mechanical reliability characterization of low carbon steel brazed joints with copper filler metal. Mater. Sci. Eng. A 528 (2011) 61466156.

[28] H.D. Solomon, G.R. Halford, L.R. Kaisand, B.N. Leis, Low Cycle Fatigue, ASTM Int., STP 942, 1988.

[29] M.K. Ghovanlou, H. Jahed, A. Khajepour, Cohesive zone modeling of ductile tearing process in brazed joints. Eng. Fract. Mech. 102 (2013) 156-170.

[30] R.C. McClung, H. Sehitoglu, On the finite element analysis of fatigue crack closure1.Basic modeling issues, Eng. Fract. Mech. 33 (2) (1989) 237-252. 
[31] T.L. Anderson, Fracture Mechanics: Fundamentals and Applications, $3^{\text {rd }}$ edition, Taylor and Francis, USA, 2005. 


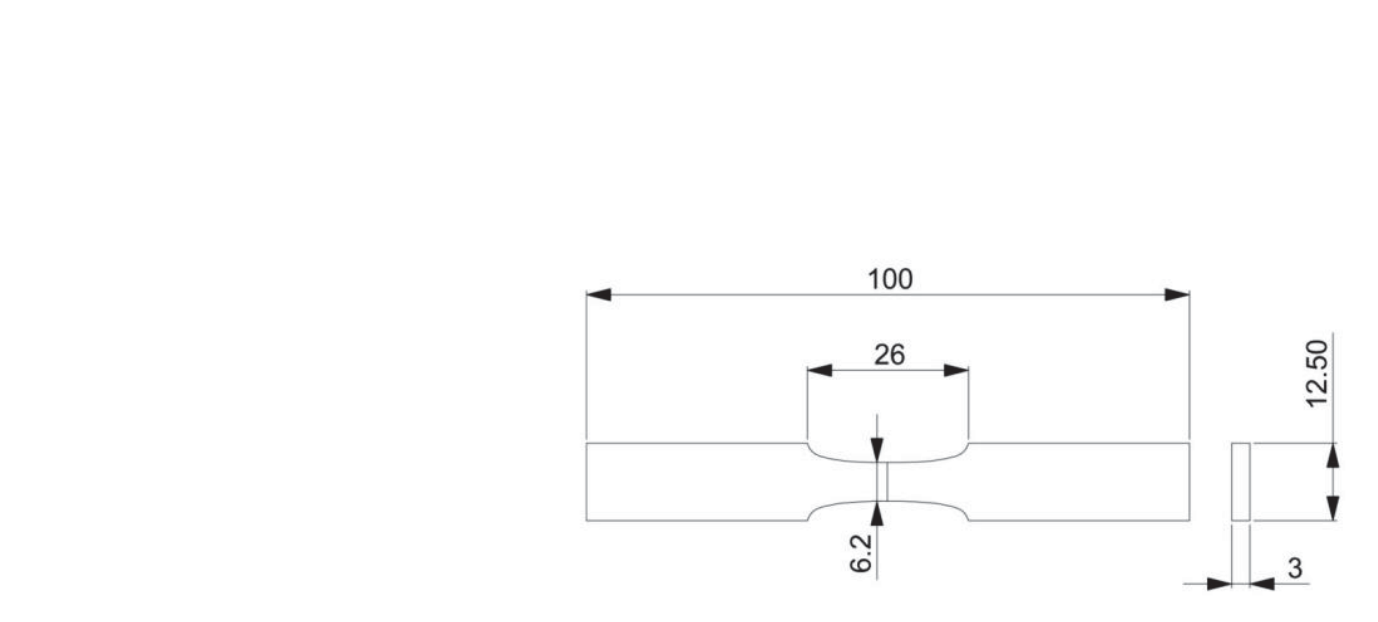

Fig.1. Dog-bone shaped fatigue specimen with a central joint (dimensions in mm)

Fig.1

Fig.1. Dog-bone shaped fatigue specimen with a central joint (dimensions in mm)

$\left[\begin{array}{ccc}2 \\ \hdashline\end{array}\right]$

Fig.1. Dog-bone shaped fatigue specimen with a central joint (dimensions in mm)

Fig.1. Dog-bone shaped fatigue specimen with a central joint (dimensions in mm)

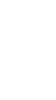

Fig.1

Fig.1. Dog-bone shaped fatigue specimen with a central joint (dimensions in mm)

Fig.1. Dog-bone shaped fatigue specimen with a central joint (dimensions in mm)

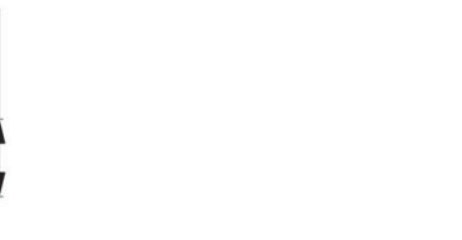

Fig.1. Dog-bone shaped fatigue specimen with a central joint (dimensions in mm)
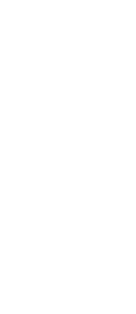
Fig.1. Dog-bone shaped fatigue specimen with a central joint (dimensions in mm) Fig.1. Dog-bone shaped fatigue specimen with a central joint (dimensions in mm) 

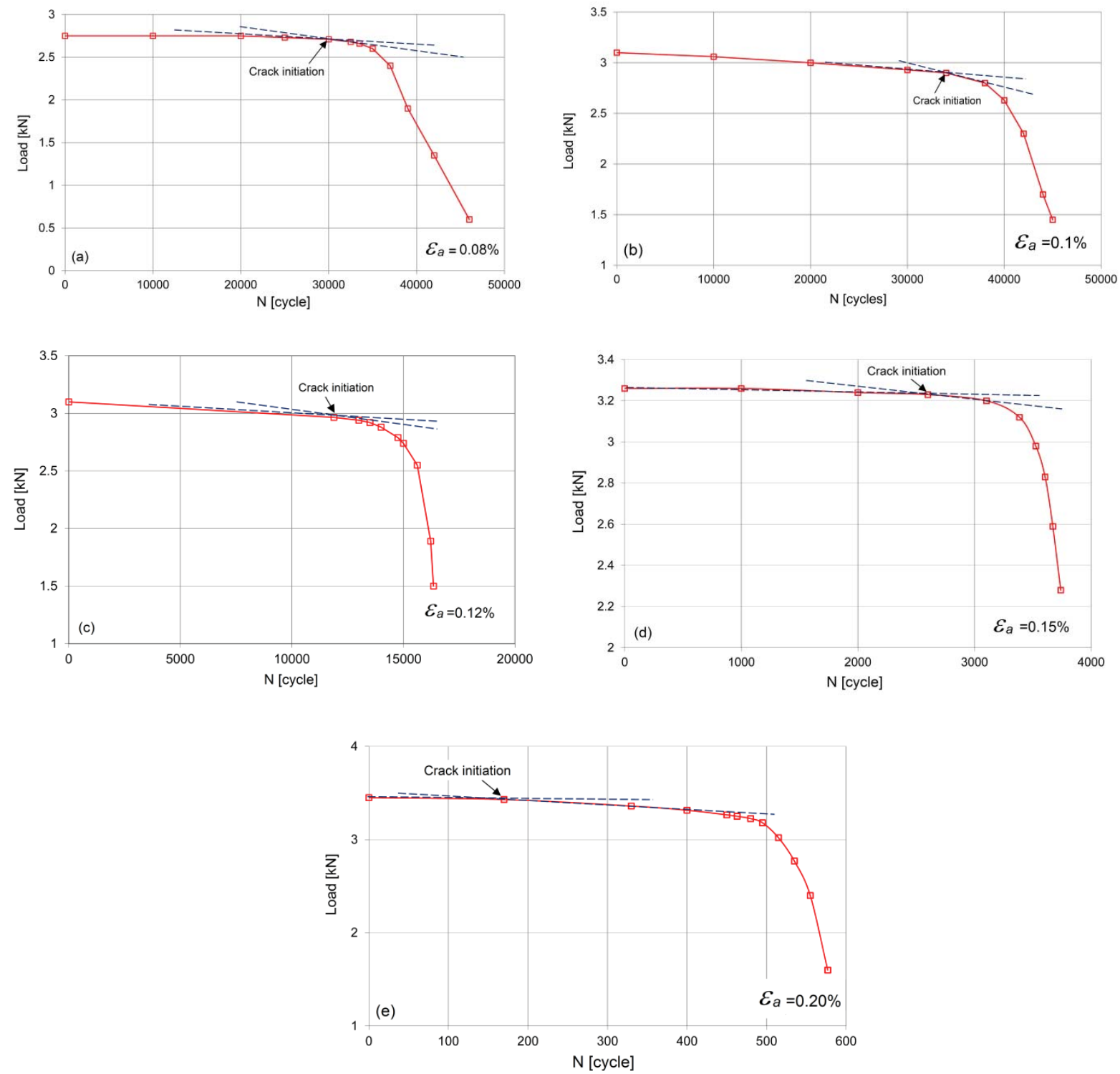

Fig.2. Load versus the number of cycles for strain amplitudes of (a) $0.08 \%$, (b) $0.10 \%$, (c) $0.12 \%$, (d) $0.15 \%$, and (e) $0.20 \%$ 


\section{Fig.3}
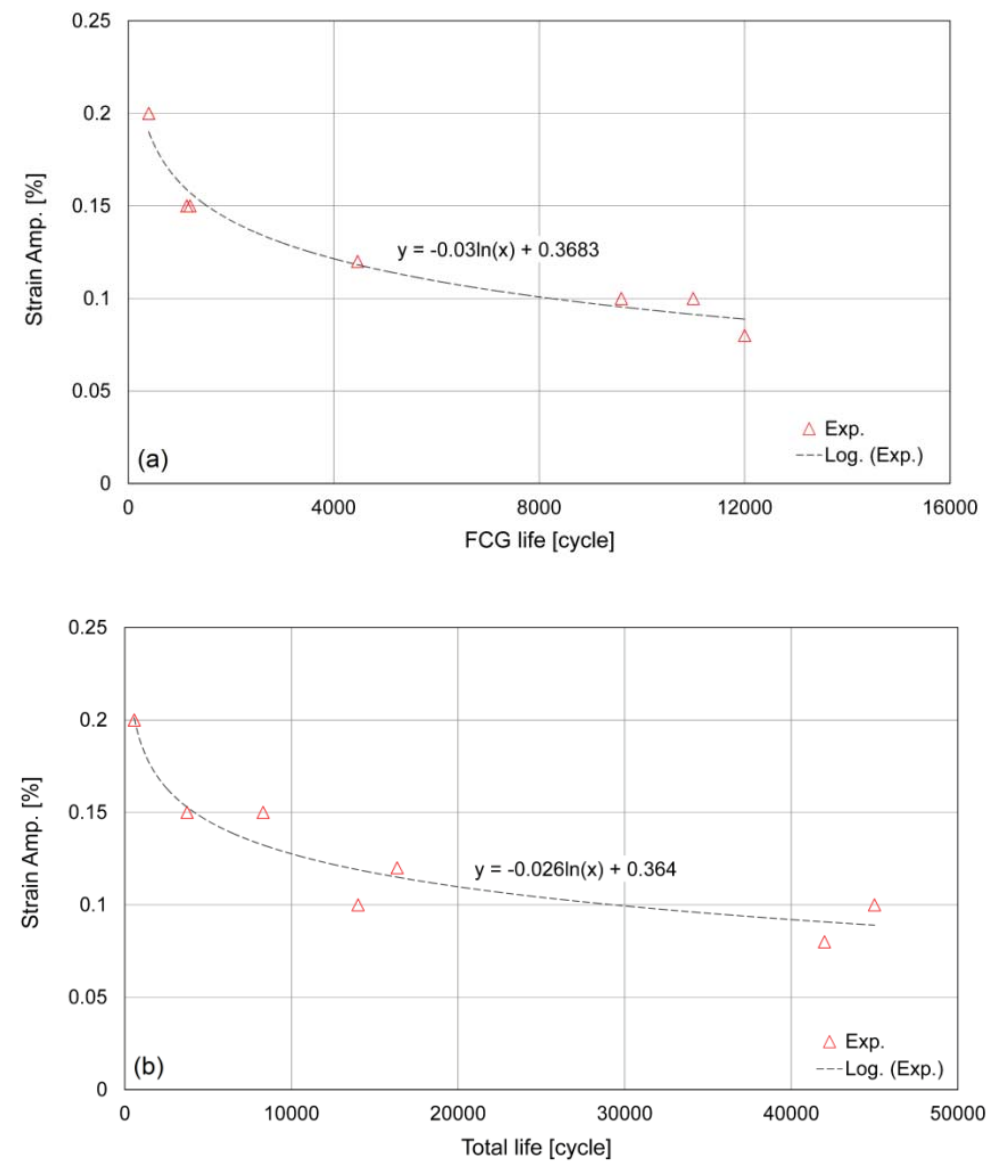

Fig.3. The experimental strain amplitudes versus (a) FCG life, (b) total fatigue life 

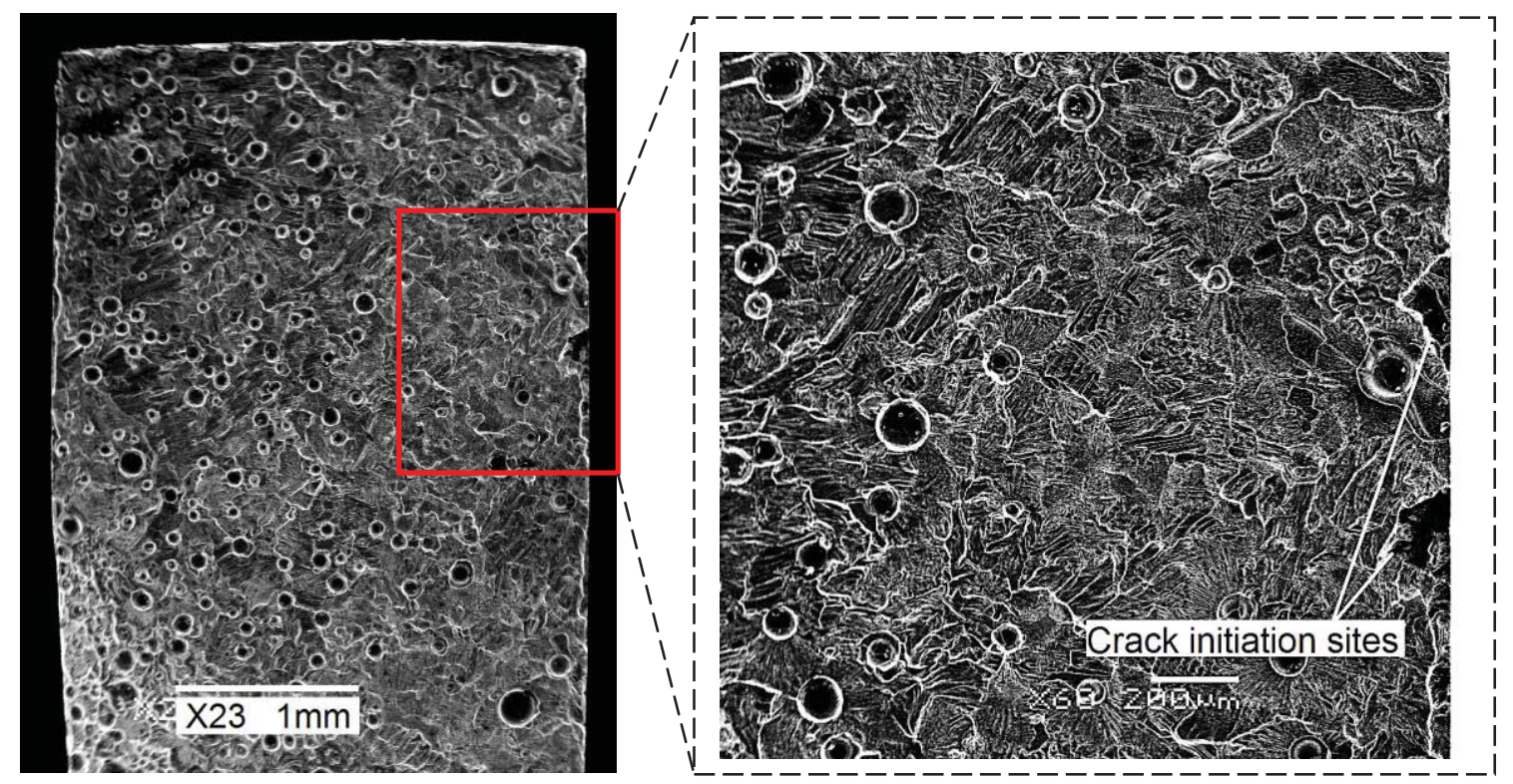

(a)

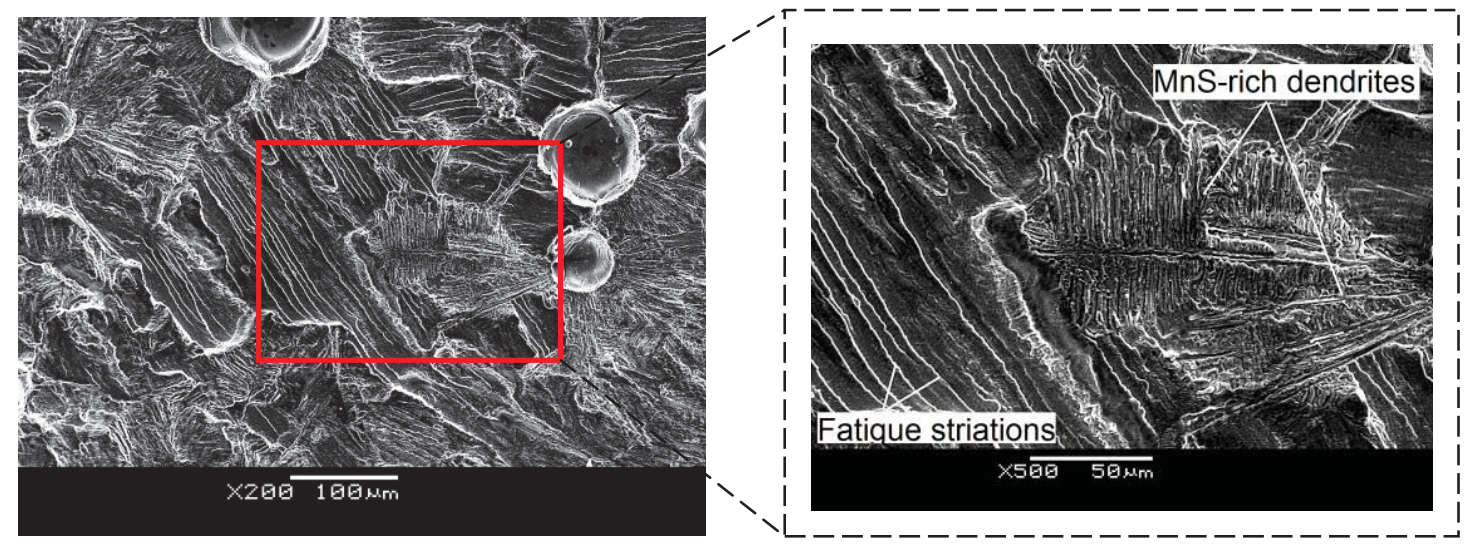

(b)

Fig.4. SEM macrographs from join fracture surface (a) crack initiation site, (b) interdendritic fatigue striation 


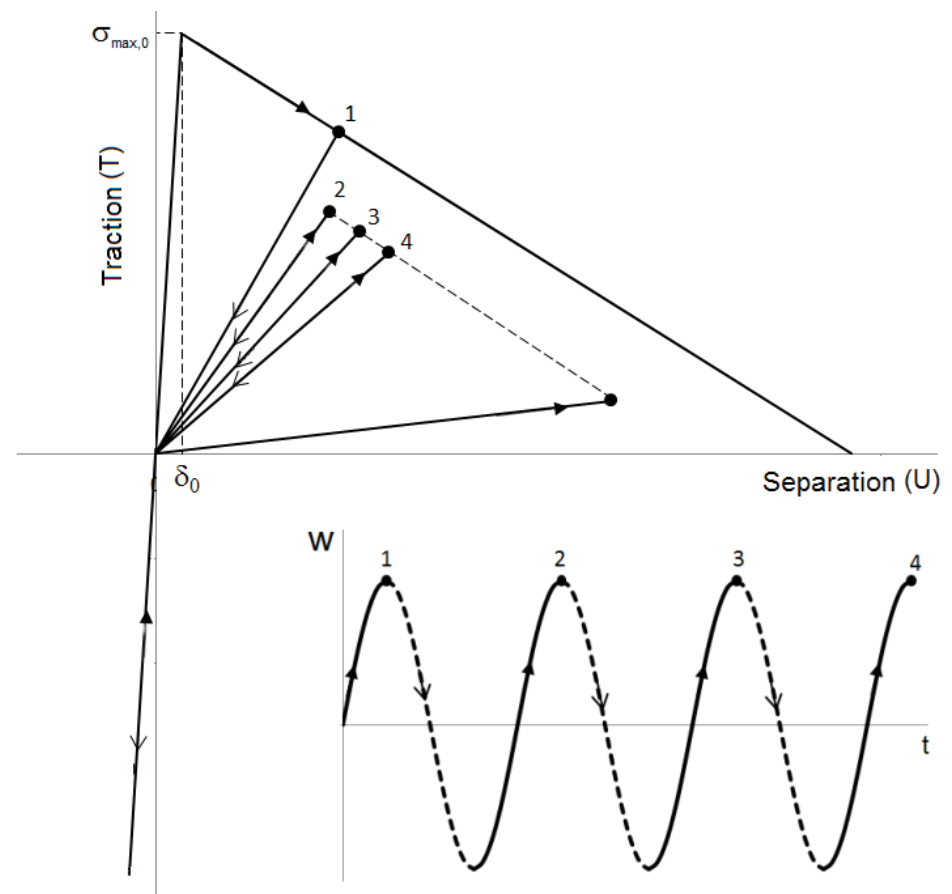

Fig.5. Applied displacement wave, $w(\mathrm{t})$, and the corresponding loading-unloading paths on the traction-separation model 


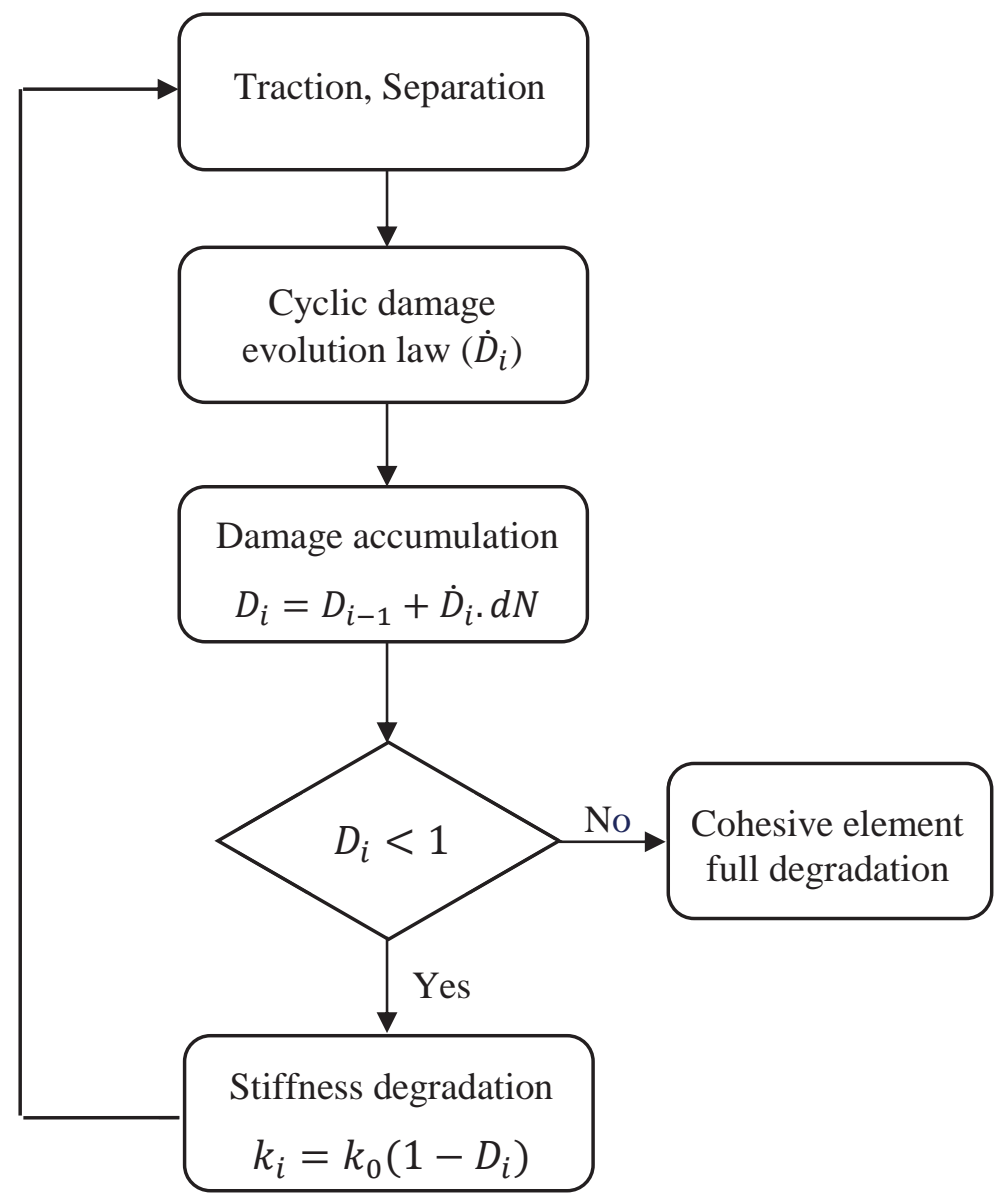

Fig.6. Flowchart of the cyclic damage analysis 

Fig.7

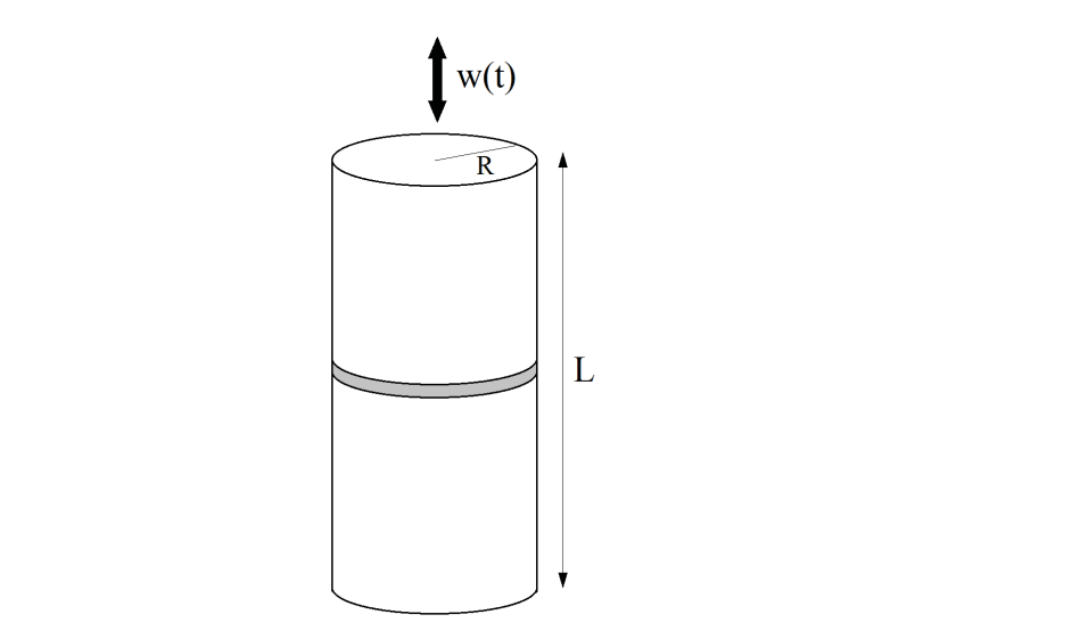

Fig.7. A rod with a central butt joint under cyclic loading

Fig.7. A rod with a central butt joint under cyclic loading

Fig.

der cyclic loading

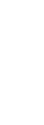

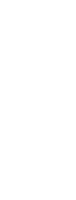

(1)

(1) 
Fig.8

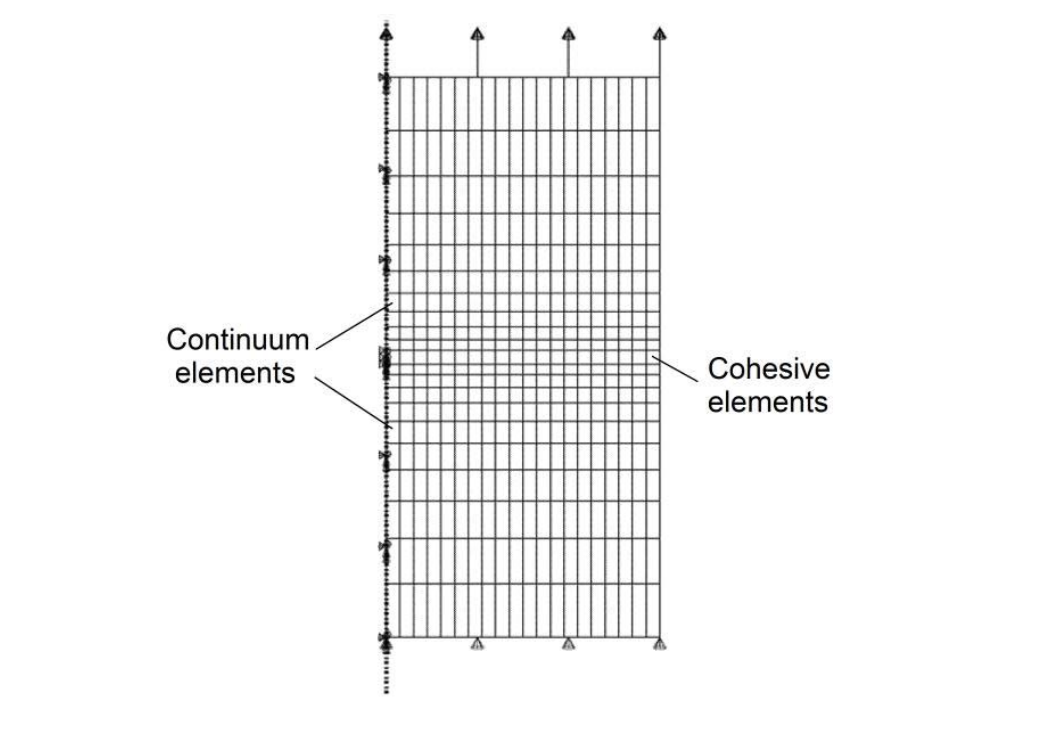

Fig.8. Axisymmetric FE model of the rod under uniaxial loading

8

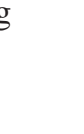




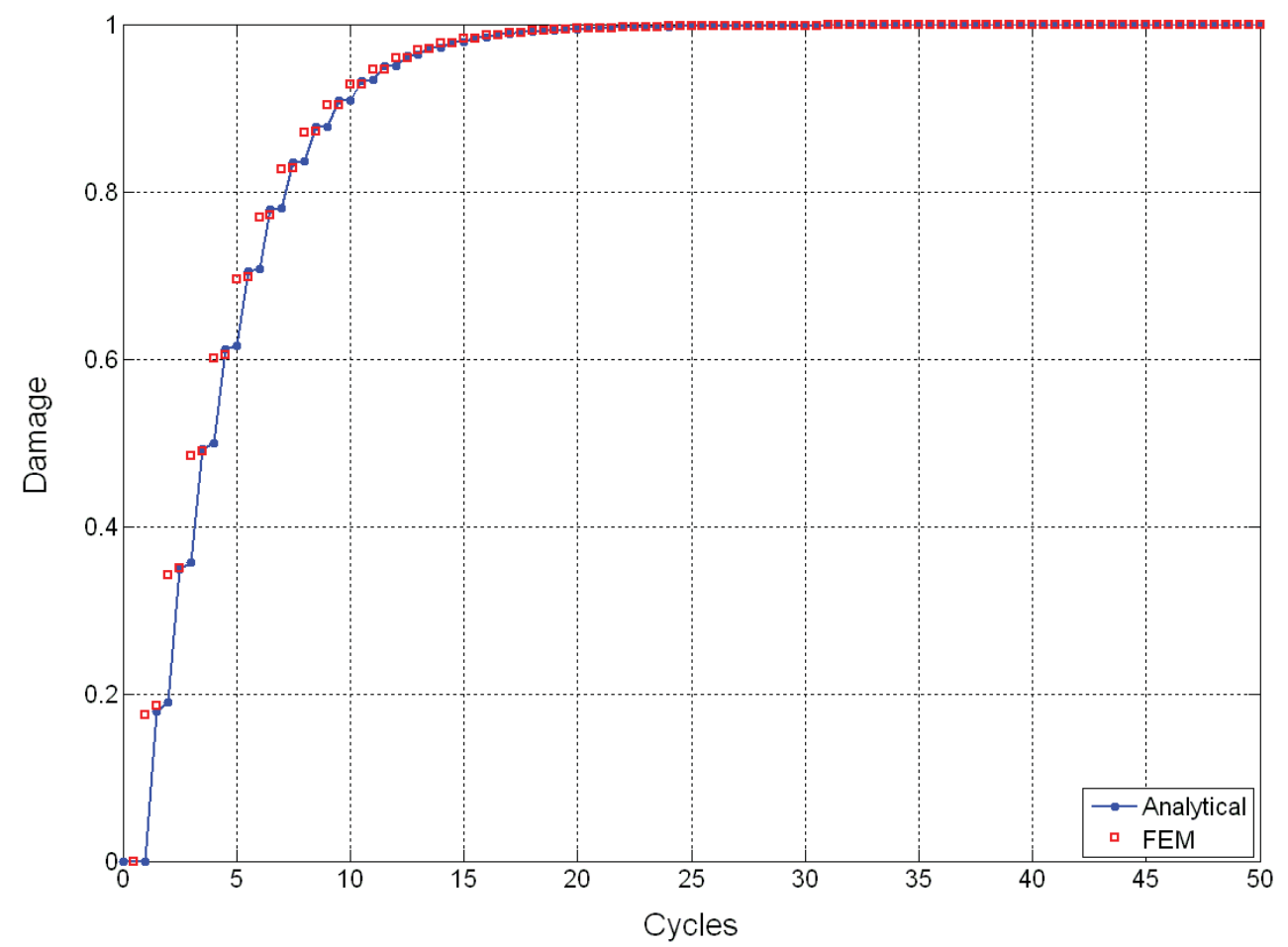

Fig.9. Damage evolution over the number of cycles from the FEM and analytical solution for butt joined rod problem 


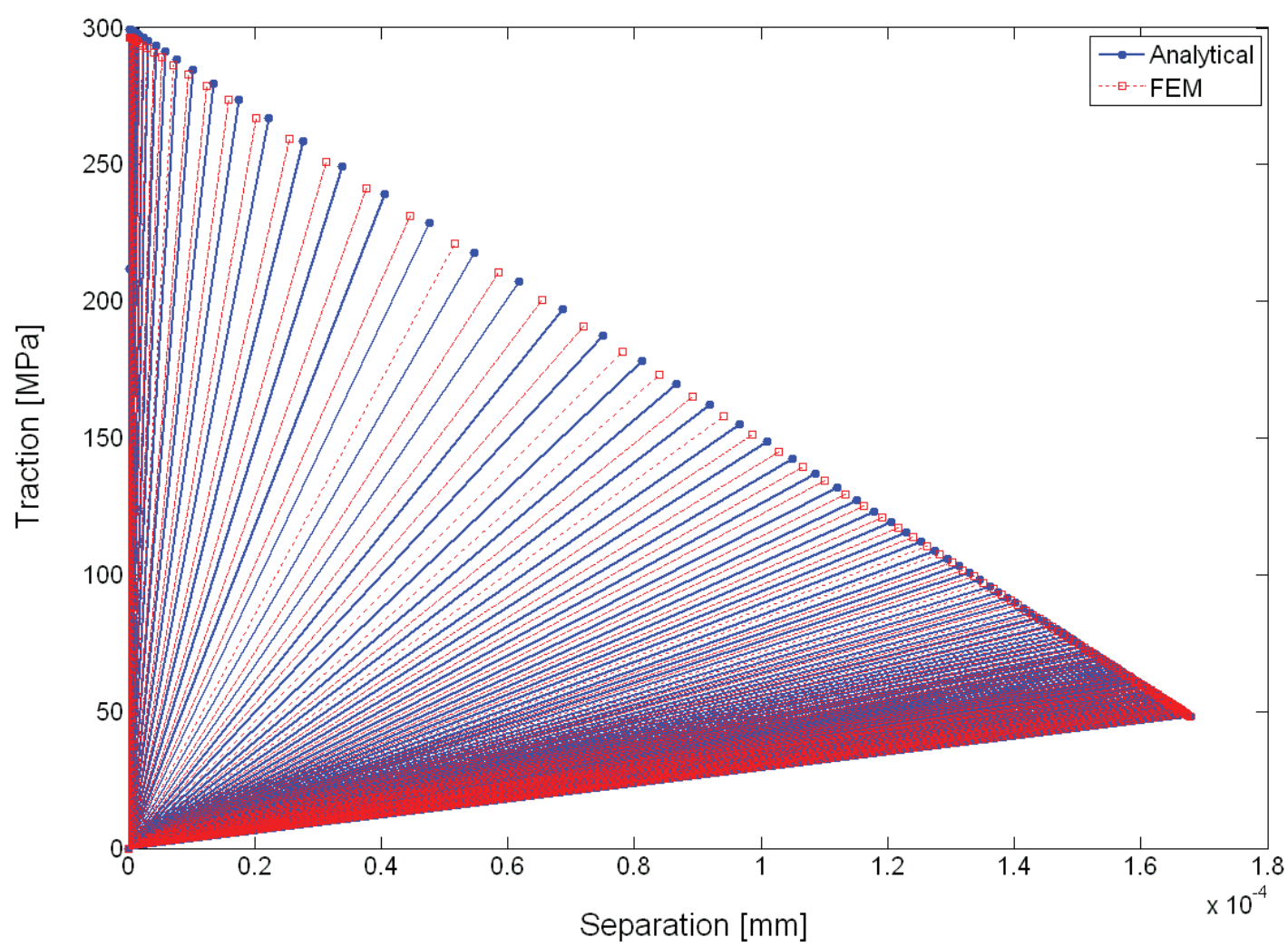

Fig.10. Cyclic traction-separation curves from the FEM and analytical solution for butt joined rod problem 
Fig.11

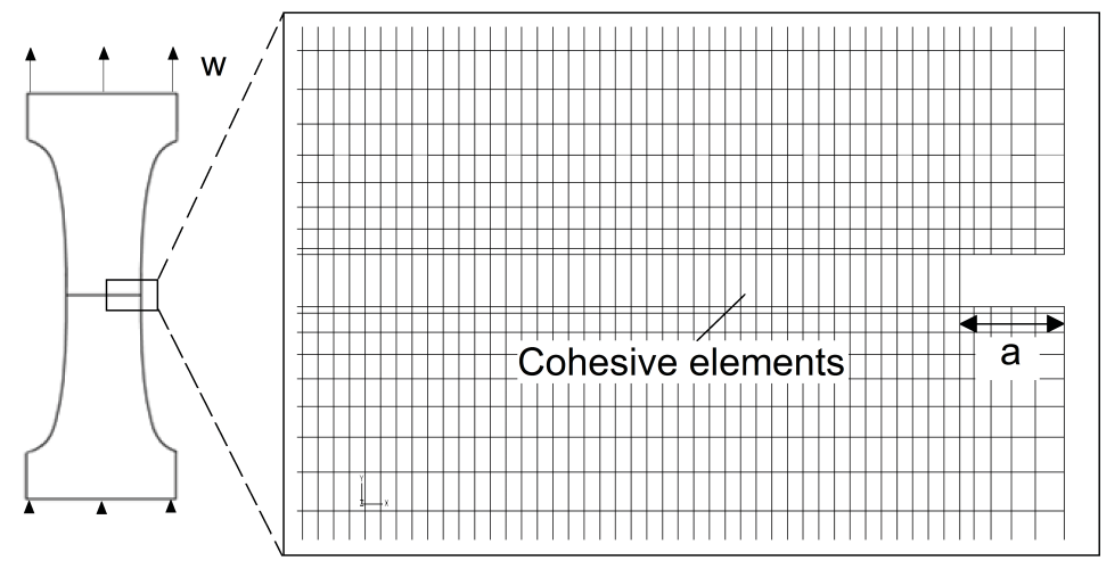

Fig.11. FE model of the fatigue specimen with an initial crack 


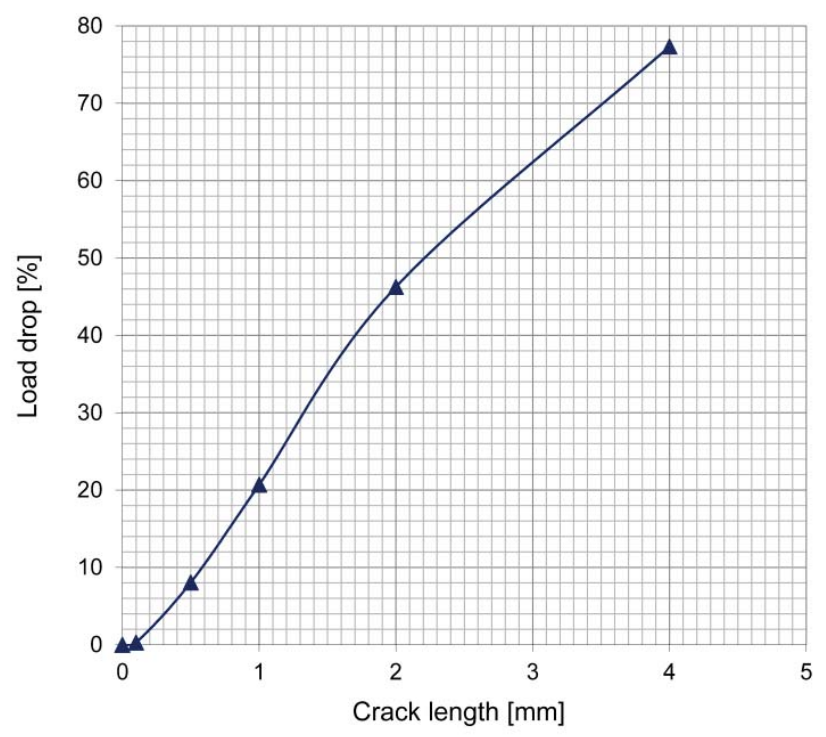

Fig.12. Load drop percentage versus the crack length created in the FE model 


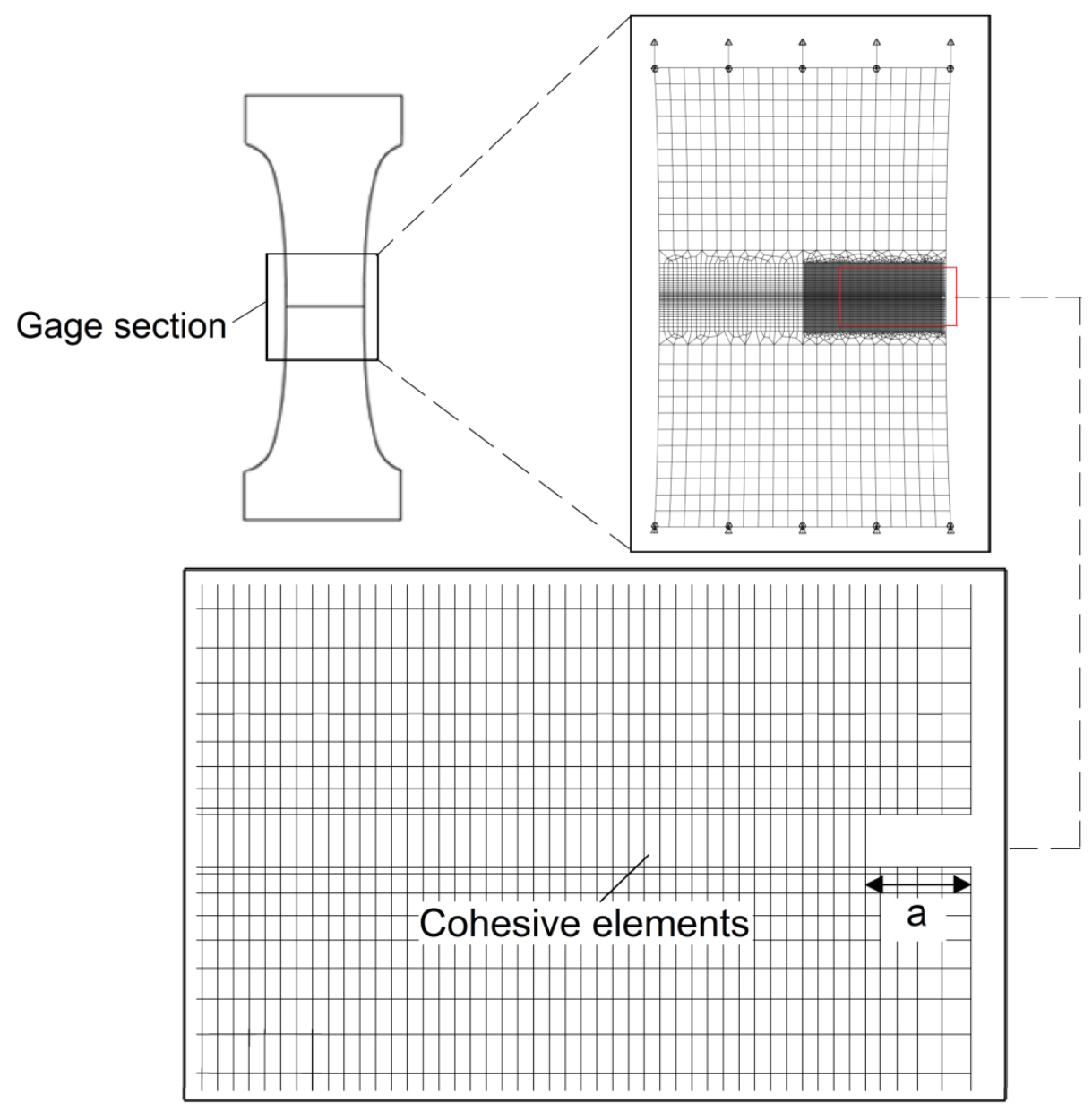

Fig.13. FE model of the fatigue specimen with an initial crack 


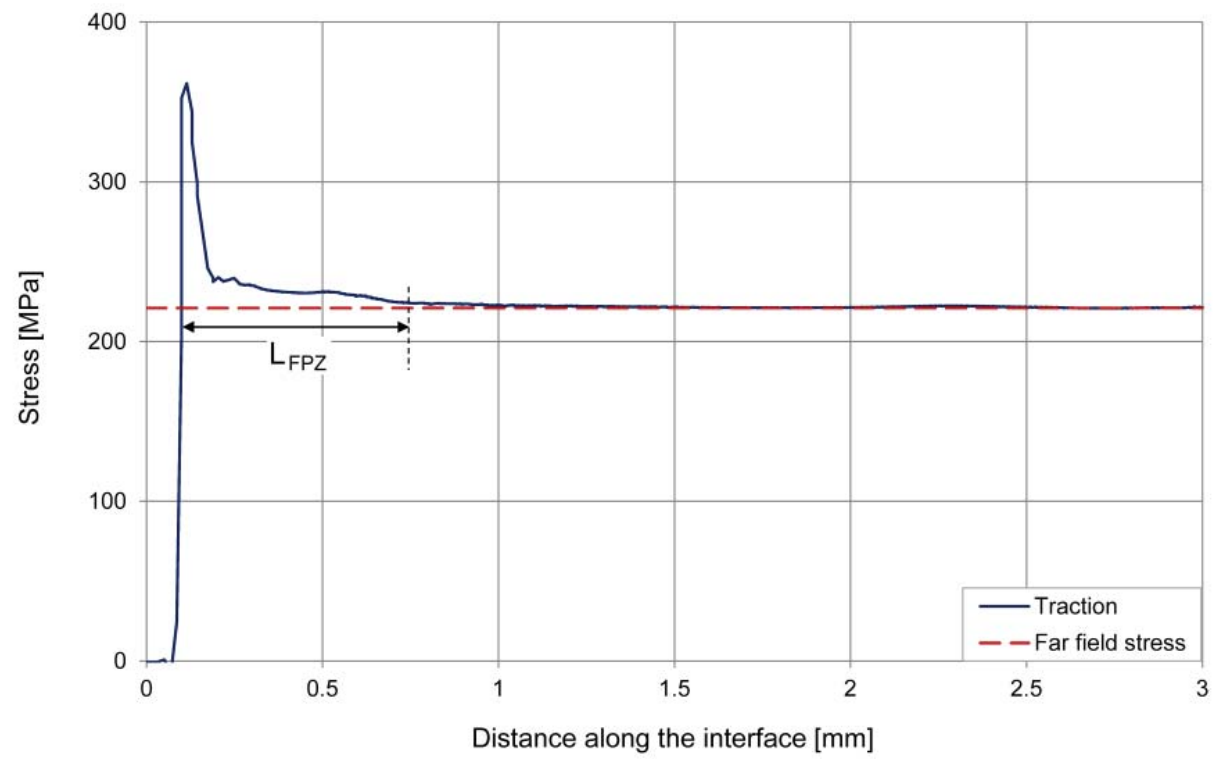

Fig.14. Traction and far field stress along the interface 


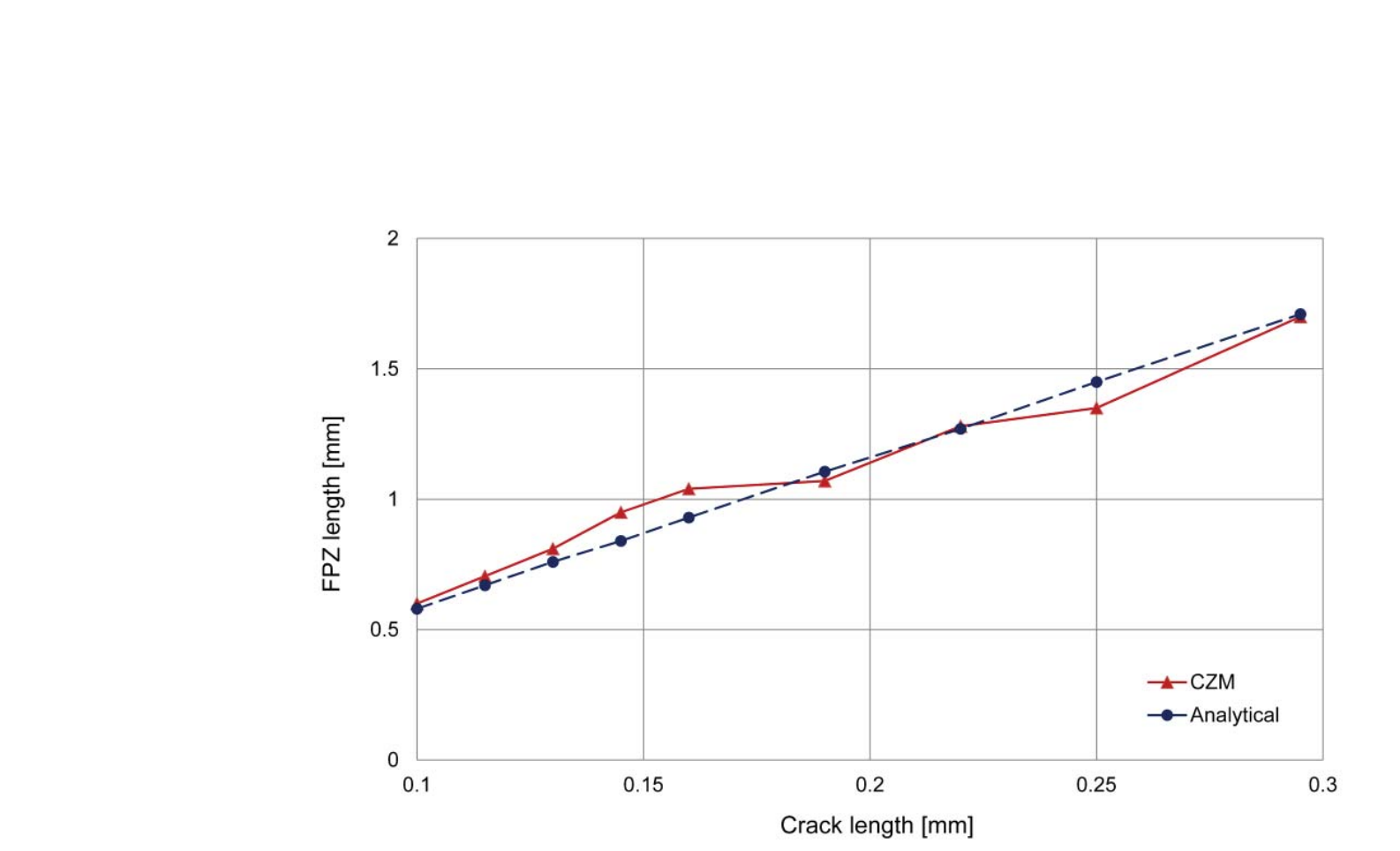

Fig.15. Analytical and numerical FPZ length with respect to the crack length for $m=1.75$

Fig.1

3

年

Fig.15. Analytical and numerical FPZ length with respect to the crack length for $m=1.75$

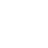

(1)

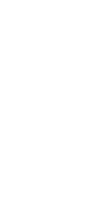

.
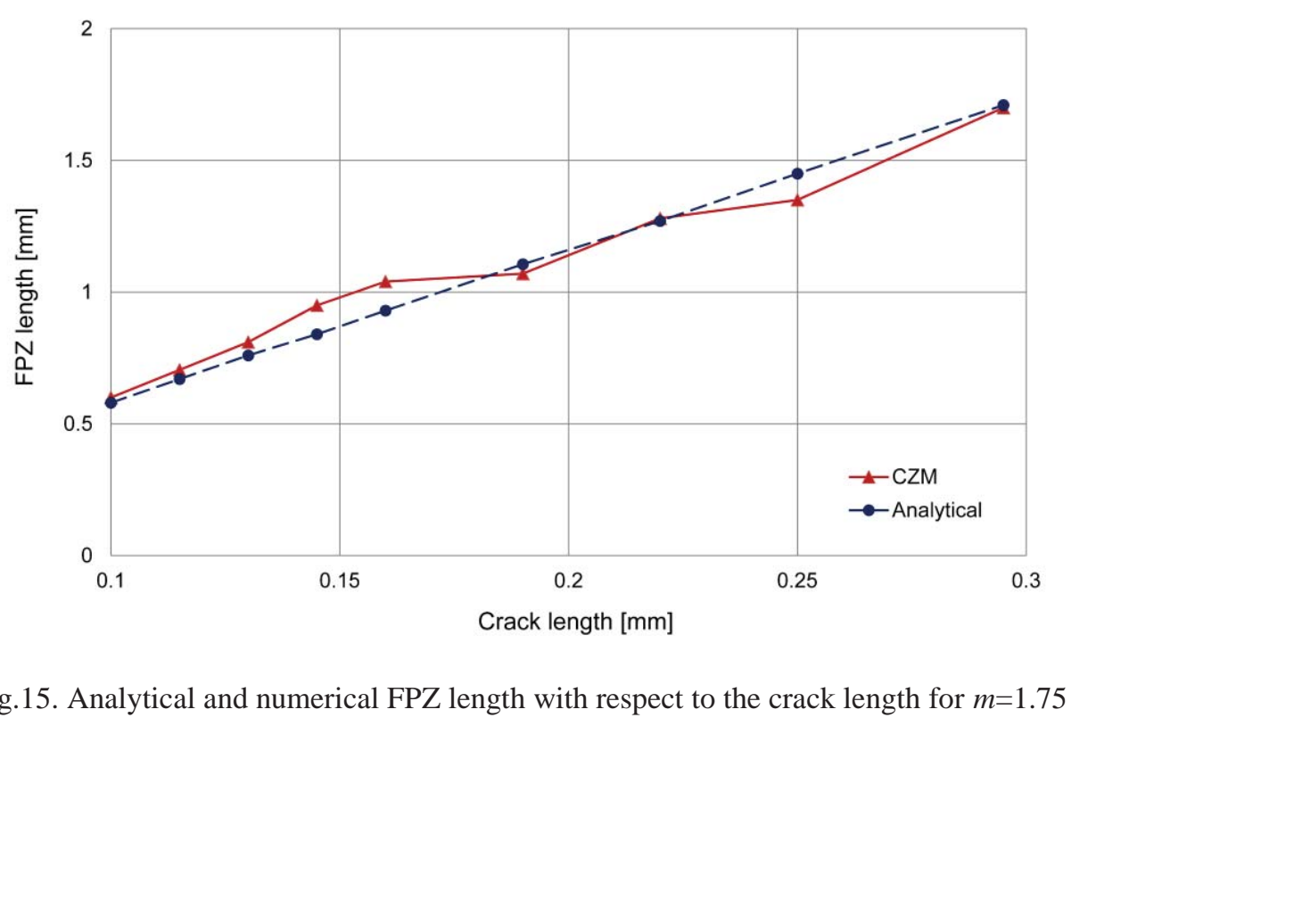


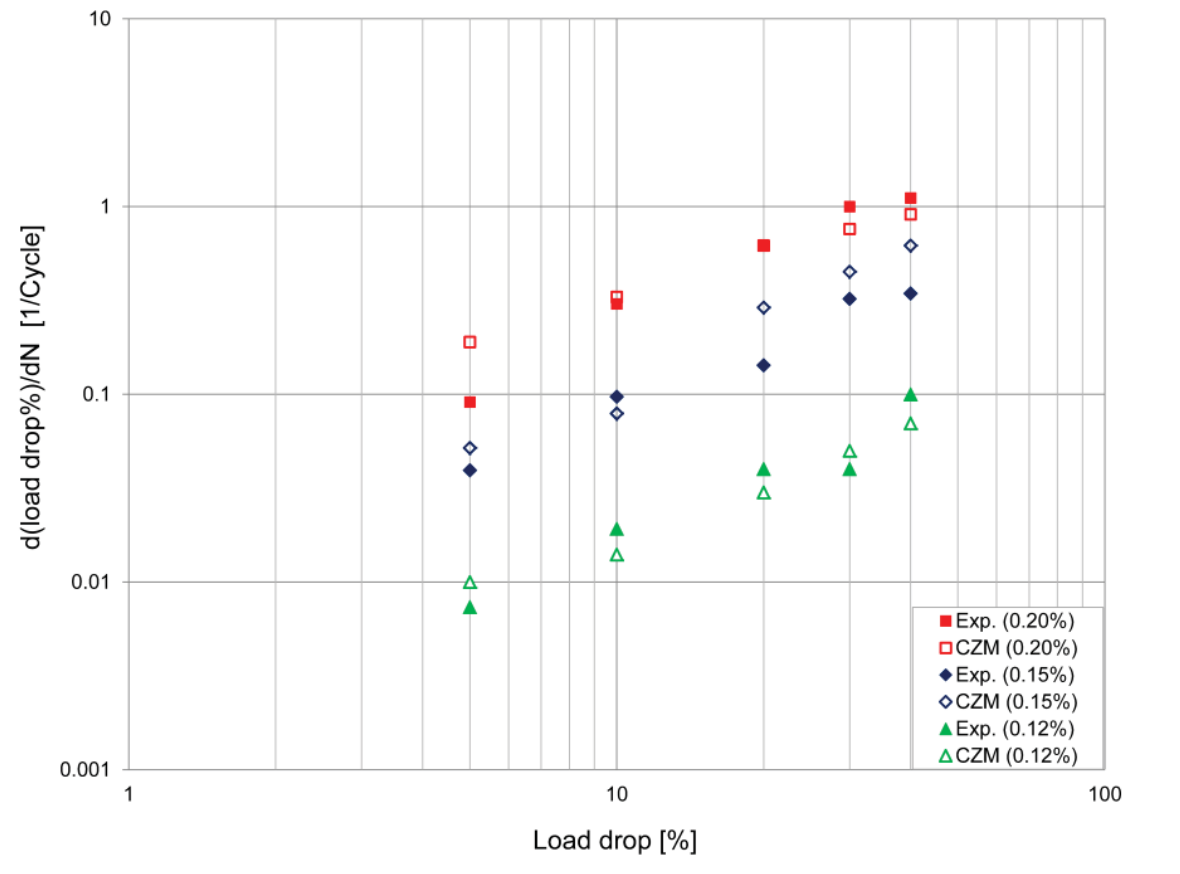

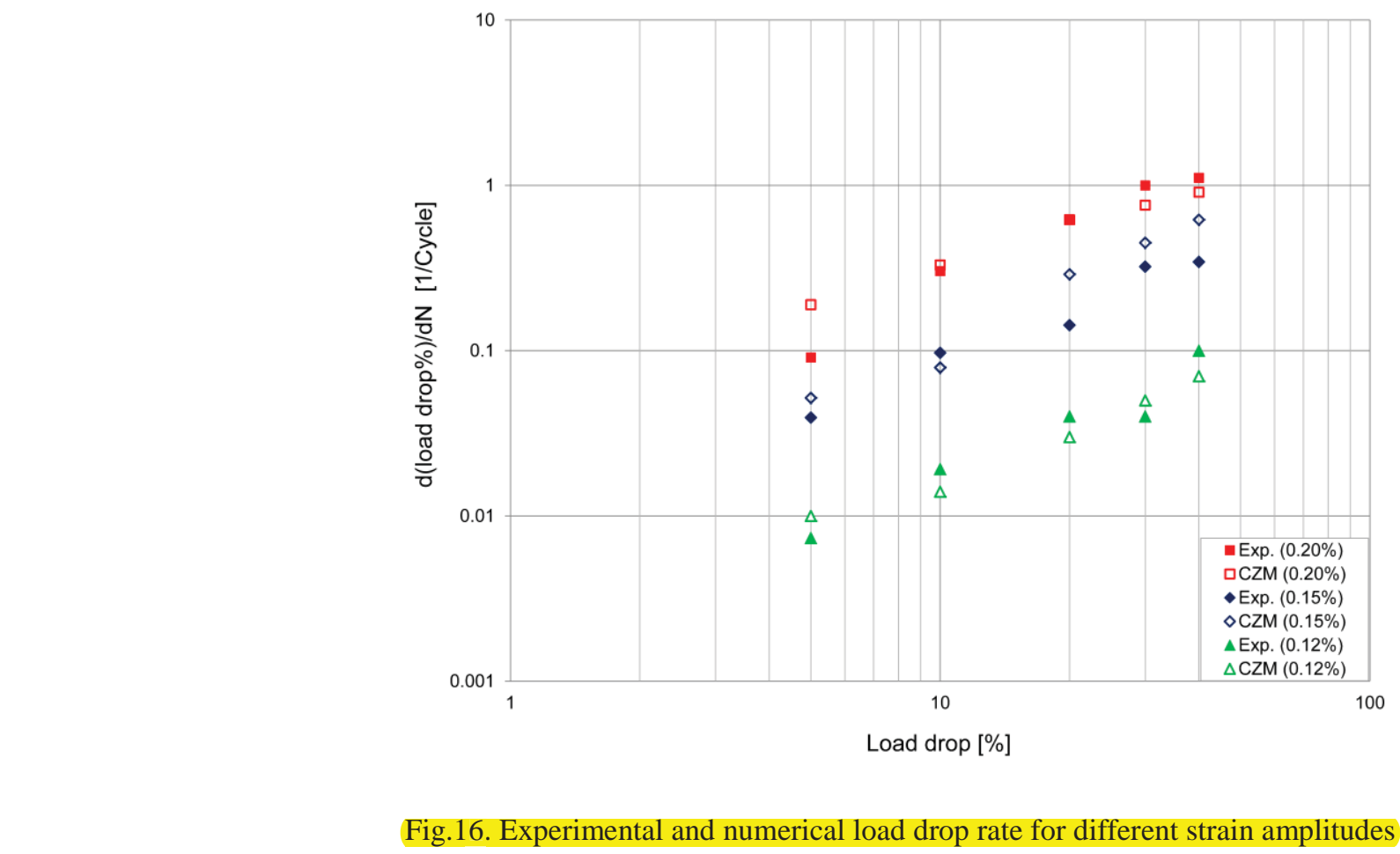

.

.

.

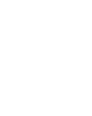
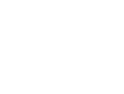

.

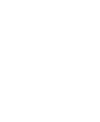



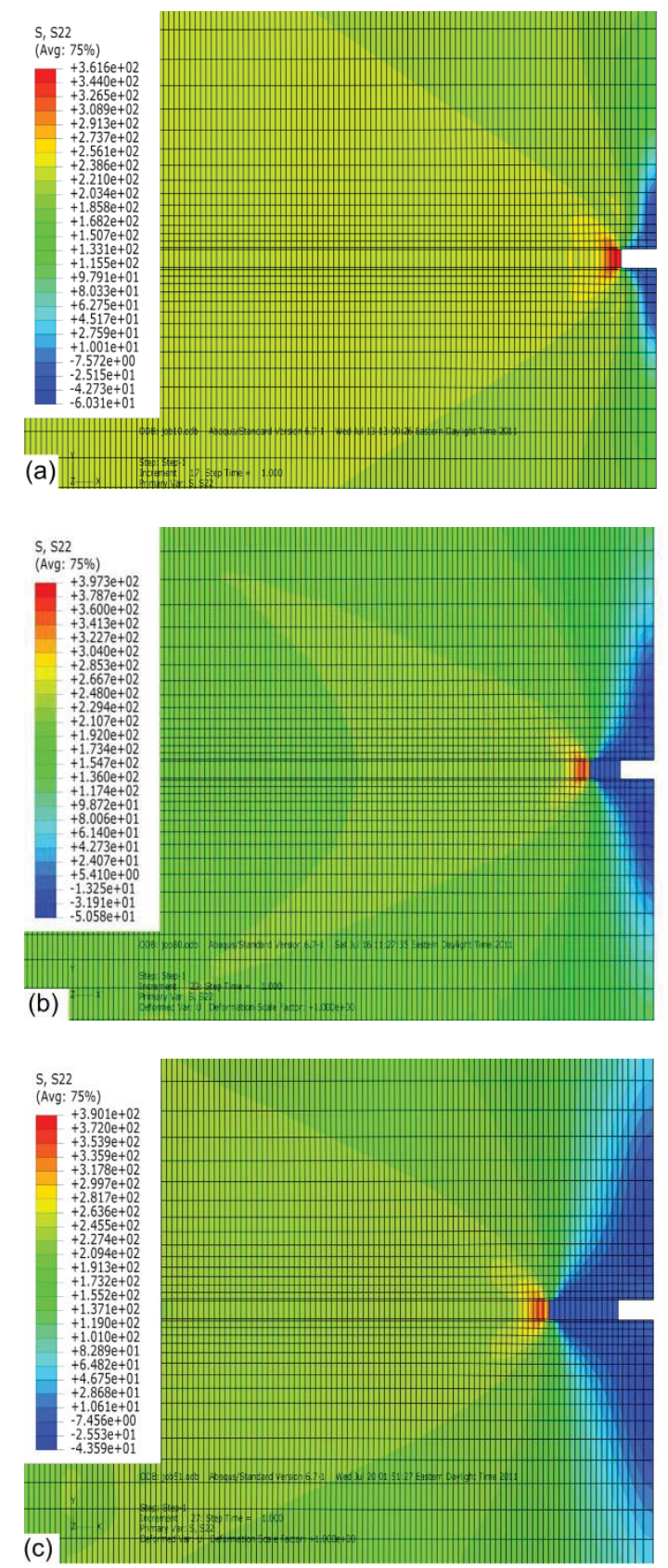

Fig.17. Contours of axial stress (S22) around the crack tip for $\varepsilon_{a}=0.15 \%$ at (a) $\mathrm{N}=2$ cycles, (b) $\mathrm{N}=500$ cycles, (c) $\mathrm{N}=800$ cycles 


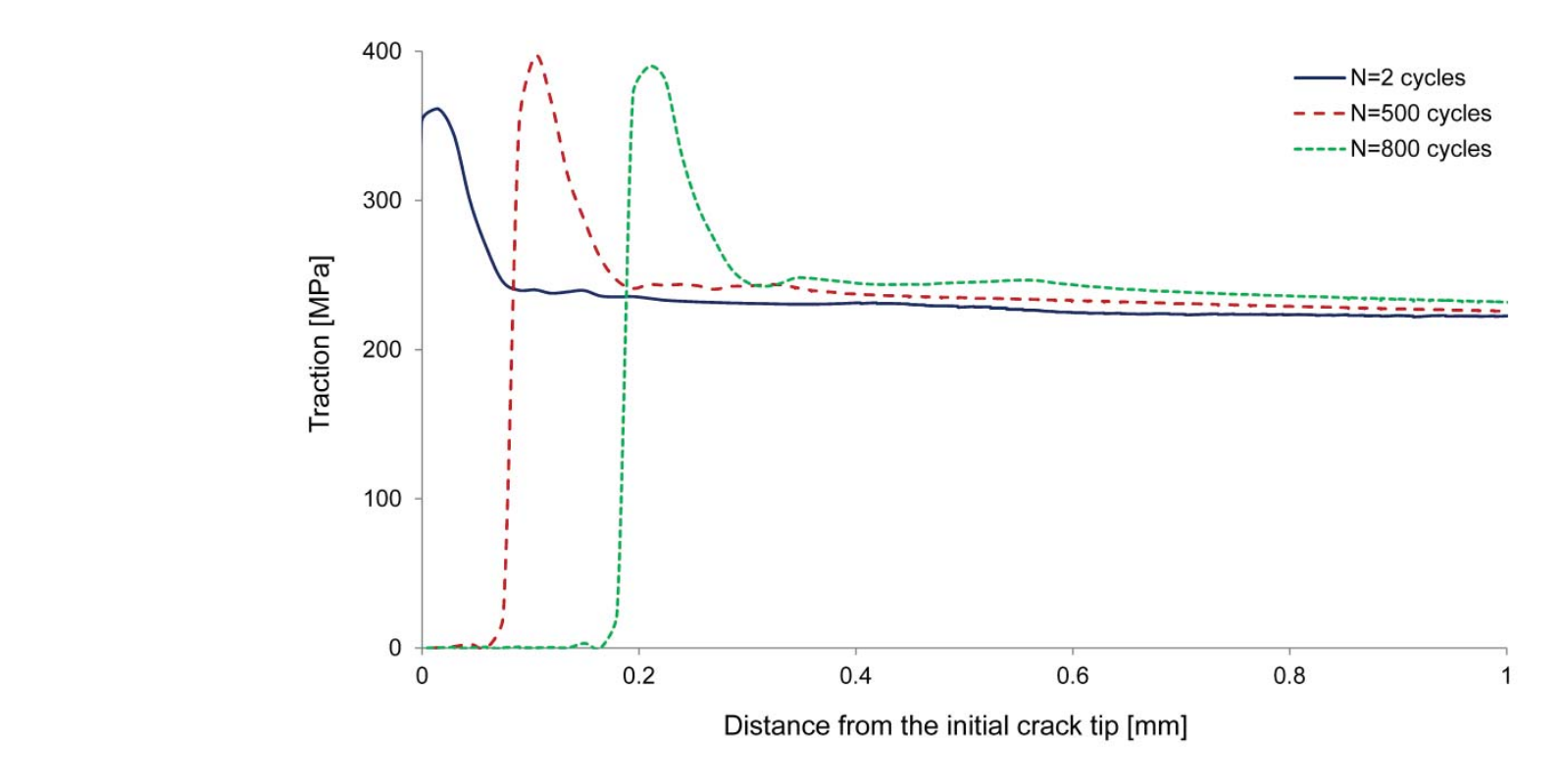

\title{
Fig.18
}

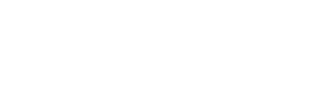
ras

\begin{abstract}
Fig.18. Traction distributions along the interface for $\varepsilon_{a}=0.15 \%$ at different cycles
\end{abstract}

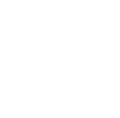

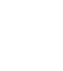

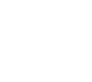

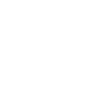

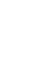

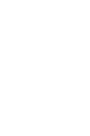
(1) 


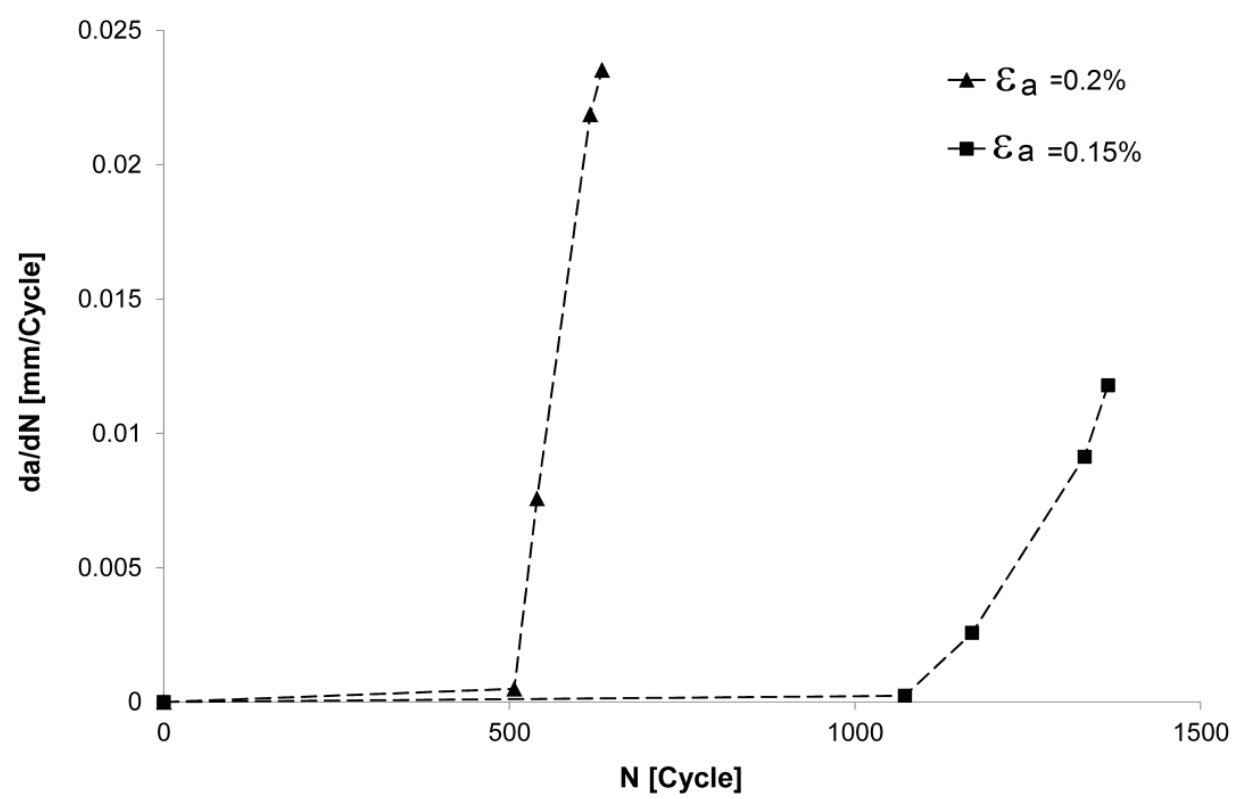

Fig.21. Crack growth rate with respect to number of cycles obtained from the CZM 


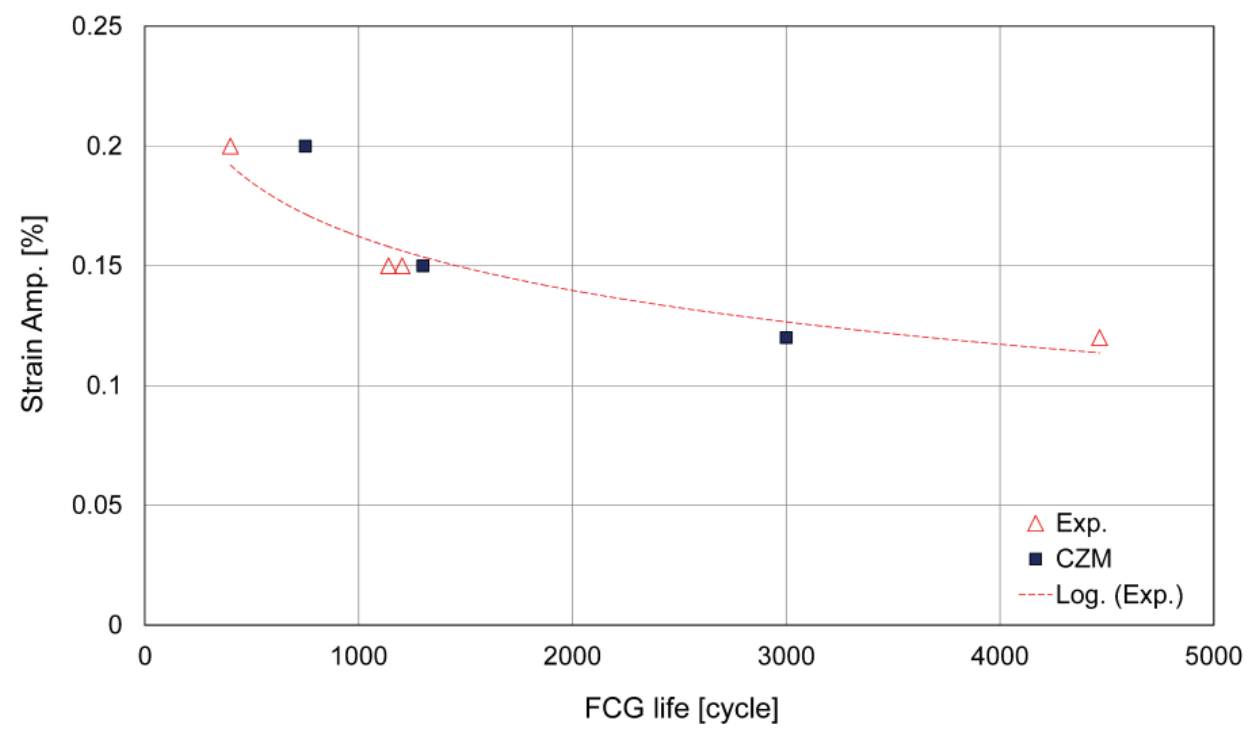

Fig.22. Experimental strain-FCG life curve in compared to the CZM results 
Table 1. Crack initiation, propagation and total lives for different strain amplitudes

\begin{tabular}{cccccc}
\hline Specimen ID. & $\begin{array}{c}\text { Strain Amp. } \\
\text { [\%] }\end{array}$ & $\begin{array}{c}\text { Initiation life } \\
\text { [cycle] }\end{array}$ & $\begin{array}{c}\text { FCG life } \\
\text { [cycle] }\end{array}$ & $\begin{array}{c}\text { Total life } \\
\text { [cycle] }\end{array}$ & $\begin{array}{c}\text { Final load } \\
\text { drop [\%] }\end{array}$ \\
\hline 3 & 0.20 & 170 & 400 & 570 & 50 \\
4 & 0.15 & 2600 & 1140 & 3740 & 50 \\
5 & 0.15 & 7100 & 1203 & 8303 & 50 \\
6 & 0.12 & 11884 & 4466 & 16350 & 50 \\
1 & 0.10 & 34000 & 11000 & 45000 & 50 \\
2 & 0.10 & 4400 & 9600 & 14000 & 50 \\
10 & 0.08 & 30000 & 12000 & 42000 & 50 \\
\hline
\end{tabular}


Table 2. Material properties and damage law parameters used in the analysis

\begin{tabular}{cc}
\hline Parameter & Value \\
\hline Young's modulus [GPa] & 30 \\
Poisson's ratio & 0.25 \\
$k_{0}\left[\frac{\mathrm{GPa}}{\mathrm{mm}}\right]$ & $1 \mathrm{e} 9$ \\
$A\left[\mathrm{MPa}^{-1} \cdot \mathrm{mm}^{-1}\right]$ & 3000 \\
$m$ & 3 \\
$n$ & 1 \\
$\mathrm{~T}_{0}[\mathrm{MPa}]$ & 100 \\
\hline
\end{tabular}


Table 3. The stress values versus the plastic strains for the base metal

\begin{tabular}{ccccccccc}
\hline $\begin{array}{c}\text { Plastic strain } \\
{[\mathrm{mm} / \mathrm{mm}]}\end{array}$ & 0 & 0.014 & 0.030 & 0.040 & 0.050 & 0.060 & 0.070 & 0.100 \\
\hline Stress [MPa] & 219 & 220 & 270 & 290 & 308 & 322 & 332 & 360 \\
\hline
\end{tabular}


Table 4. Calculation of the maximum size of the cohesive elements

\begin{tabular}{ccccccc}
\hline$\varepsilon_{\boldsymbol{a}}[\%]$ & $\boldsymbol{\sigma}_{\infty}[\mathbf{M P a}]$ & $\boldsymbol{a}[\mathbf{m m}]$ & $\boldsymbol{K}_{\boldsymbol{I}}[\mathbf{M p a} \sqrt{\boldsymbol{m}}]$ & $\boldsymbol{T}_{\mathbf{0}}[\mathbf{M P a}]$ & $\boldsymbol{L}_{F P Z}[\mathbf{m m}]$ & $\boldsymbol{L}_{e, C Z M}[\mathbf{m m}]$ \\
\hline 0.10 & 198 & 0.1000 & 3.5095 & 100 & 0.3920 & 0.0392 \\
\hline
\end{tabular}


Table 5. Parameters used in FCG analysis

\begin{tabular}{ccccc}
\hline $\boldsymbol{k}_{\mathbf{0}}[\mathrm{GPa} / \mathbf{m m}]$ & $\boldsymbol{A}\left[\mathrm{MPa}^{-\mathbf{1}} \cdot \mathbf{m m}^{-\mathbf{1}}\right]$ & $\boldsymbol{n}$ & $\boldsymbol{\sigma}_{\max , \mathbf{0}}[\mathrm{MPa}]$ & $\boldsymbol{T}_{\mathbf{0}}[\mathrm{MPa}]$ \\
\hline 1640 & 0.05 & 1 & 400 & 100 \\
\hline
\end{tabular}


Table 6. Values of the parameter $A$ obtained for different strain amplitudes

\begin{tabular}{cc}
\hline $\boldsymbol{\varepsilon}_{\boldsymbol{a}}[\%]$ & $\boldsymbol{A}\left[\mathbf{M P a}^{\mathbf{- 1}} \cdot \mathbf{m m}^{-\mathbf{1}}\right]$ \\
\hline 0.12 & 0.009 \\
0.15 & 0.031 \\
0.20 & 0.060 \\
\hline
\end{tabular}

